Sādhanā Vol. 29, Part 1, February 2004, pp. 93-115. (C Printed in India

\title{
Experimental investigations on buckling of cylindrical shells under axial compression and transverse shear
}

\author{
$\mathrm{K}_{\text {ATHIANNAN }}{ }^{a}$ and R PALANINATHAN ${ }^{b, *}$ \\ ${ }^{a}$ Structural Mechanics Section, Reactor Engineering Group, Indira Gandhi Centre \\ for Atomic Research, Kalpakkam 603 102, India \\ ${ }^{b}$ Department of Applied Mechanics, Indian Institute of Technology - Madras, \\ Chennai 600 036, India \\ e-mail: rpnathan@iitm.ac.in
}

MS received 7 March 2003; revised 19 July 2003

\begin{abstract}
This paper presents experimental studies on buckling of cylindrical shell models under axial and transverse shear loads. Tests are carried out using an experimental facility specially designed, fabricated and installed, with provision for in-situ measurement of the initial geometric imperfections. The shell models are made by rolling and seam welding process and hence are expected to have imperfections more or less of a kind similar to that of real shell structures. The present work thus differs from most of the earlier investigations. The measured maximum imperfections $\delta_{\max }$ are of the order of $\pm 3 t(t=$ thickness). The buckling loads obtained experimentally are compared with the numerical buckling values obtained through finite element method (FEM). In the case of axial buckling, the imperfect geometry is obtained in four ways and in the case of transverse shear buckling, the FE modelling of imperfect geometry is done in two ways. The initial geometric imperfections affect the load carrying capacity. The load reduction is considerable in the case of axial compression and is marginal in the case of transverse shear buckling. Comparisons between experimental buckling loads under axial compression, reveal that the extent of imperfection, rather than its maximum value, in a specimen influences the failure load. Buckling tests under transverse shear are conducted with and without axial constraints. While differences in experimental loads are seen to exist between the two conditions, the numerical values are almost equal. The buckling modes are different, and the experimentally observed and numerically predicted values are in complete disagreement.
\end{abstract}

Keywords. Cylindrical shell models; axial compression; transverse shear; initial geometric imperfections; buckling loads; finite element method.

\footnotetext{
*For correspondence

A list of symbols is given at the end of the paper
} 


\section{Introduction}

For thin-walled structures under net compressive stress, the stability criterion controls the design, as the structure fails due to loss of stability at stress level much lower than the yield stress. If the shell is loaded in such a way that most of its strain energy is in the form of membrane compression and if there is a way that this stored-up membrane energy can be converted into bending energy, the shell fails dramatically in a process called buckling, as it exchanges its membrane energy for bending energy. Very large deflections are generally required to convert a given amount of membrane energy into bending energy. In other words, the structure goes from one equilibrium position (prebuckling state) to another (buckled state); i.e., it has multiple equilibrium configurations. The classical buckling equations available in standard texts are derived based on the above concept. The above idealised conditions are not seen to exist in real structures and hence the values obtained from the classical equations are very high and hence are unrealistic. This situation has prompted the structural analysts to study extensively the buckling problems experimentally.

In pool-type liquid metal fast breeder reactor (LMFBR) design, the main vessel, an unstiffened thin circular cylindrical shell with torispherical bottom, is one of the important components and the design of such structures is controlled by the seismic loading during which the vessel is subjected to horizontal shear and bending. The radius-to-thickness ratio of this vessel is very large, $250<R / t<400$ and is prone to fail by buckling. The buckling strength of cylindrical shells due to bending is obtained experimentally by treating it as equivalent to that under axial compression. Since the main vessel is classified as a class 1 component, according to the ASME Boiler and Pressure Vessel Code, the structural integrity has to be checked experimentally to validate the design. Keeping this in mind, a test programme has been formulated at the Indira Gandhi Centre for Atomic Research (IGCAR), Kalpakkam to carry out experimental studies on scale models of circular cylindrical shells under axial compression and transverse shear loads.

\section{Brief literature survey}

\subsection{Axial compression}

Studies on shell buckling were started about 150 years ago by Fairban in England and the motivation was the design of tubular bridges, a civil engineering application. Developments in boiler design for mechanical and marine applications kindled further interest on shell buckling studies. Subsequently, advances in aerospace and nuclear fields increased the awareness and the need for experimental studies on unstiffened and stiffened shells. Considerable amount of literature exists on buckling studies carried out by the earlier researchers. Here only a few are cited for want of space. Historical developments in this field may be obtained from three recent review papers (Bushnell 1981; Teng 1996; Singer 1997). Failure of thin-walled cylinders under uniform axial compression seems to have been investigated first by Lily (1905-1907) as reported by Lundquist (1933). It appears that until Robertson carried out the experiments on shell buckling during the late 1920s, there were no test results available to compare with the theory. Babcock \& Sechler (1962), Tennyson (1964), Weingarten et al (1965), Waeckel et al (1984) and Schneider et al (1996) are a few of those who have carried out buckling experiments on cylindrical shells in the elastic region. Tests have been conducted on scale models made by processes such as spin casting, electroforming etc. The geometric details are radius ranging from 66 to $380 \mathrm{~mm}$, height ranging from 70 to $570 \mathrm{~mm}$ and thickness 
varying from $0 \cdot 1$ to $2 \mathrm{~mm}$. Initial geometric imperfections of specified magnitude and shape were introduced intentionally in to the models. The magnitude of imperfections ranged from $0 \cdot 5-7.8 t$. Experimental buckling loads obtained ranged from 0.85 to 0.5 times the classical values.

Gerard (1956), Lee (1962), Sobel \& Newman (1980) conducted axial buckling experiments in the inelastic region. Geometric details of the specimens used by them were: thickness ranging from 0.3 to $5.1 \mathrm{~mm}$, height varying from 6 to $509 \mathrm{~mm}$ and radius ranging from 33 to $51 \mathrm{~mm}$. Seamless tubes of $R / t<50$ were used by Gerard (1956). Imperfections were not measured. Lee (1962) used aluminium alloy tubes for his experiments. Imperfections were measured and the minimum value was $0.06 t$ in the case of thicker shell and $2.4 t$ for thinner shells. Sobel \& Newman (1980) carried out experiments using stainless steel 304 tubes. Imperfections were not measured. They compared the experimental buckling loads with the empirical formulae developed by the other researchers.

The observations of the earlier studies may be summerised as follows: In the elastic region, (i) a wide scatter exists between the experimental buckling loads of models of the same nominal dimensions, (ii) considerable discrepancy between the experimental and classical values is common, (iii) discrepancy increases with increasing radius-to-thickness ratios. The reasons attributed are: (i) presence of initial geometric imperfections, (ii) presence of material nonlinearity, (iii) eccentricity in loading and (iv) influence of boundary conditions. In the inelastic region, the initial geometric imperfections do not have much influence on the buckling load.

On the analytical side, it has been established that the presence of initial geometric imperfection changes the character of buckling analysis from a classical eigenvalue to a nonlinear problem. The analyst has to follow the load-deflection path and predict failure either at the limit point or at the bifurcation point. In the numerical modelling of imperfect geometries, the method of eigen mode injection has been adopted by many authors. This is a two-stage process in which first, the critical eigen mode is obtained and, second, this eigen mode is perturbed/renormalised using the magnitude of assumed initial geometric imperfection or experimentally observed value. Very few studies have been reported on modelling the structure using real imperfection (Schneider et al 1996).

\subsection{Shear buckling}

Lundquist (1935) was the first to investigate the buckling of circular cylindrical shells under transverse shear. Galletly \& Blachut (1985) carried out shear buckling tests on steel specimen using a special setup (the Liverpool test setup). They compared the experimental values with the analytical values obtained using an interaction formula. The tests were repeated on the buckled specimen by applying the load in the reverse direction and the buckling occurred at about $90 \%$ of the first test. This helped to prove that the cylindrical shells under transverse shear are sensitive but not significantly to the initial imperfections and also that they have good amount of strength retention even after buckling. The number of investigations on shear buckling of cylindrical shells is small in comparison to that of the axial buckling studies. Some of these in the last 15 years are by Kokubu et al (1987), Kawamoto et al (1993), Murakami et al (1993), Matsuura et al (1995) and Saito et al (2001). Developments in nuclear technology, particularly, the pool-type reactors, have stimulated these studies. The objective seems to be the evaluation of the procedure for predicting buckling loads using FEM and empirical formulae by verification against the experimentally obtained buckling loads. Tests have been conducted on scale models with a range of geometrical parameters: radii $70-500 \mathrm{~mm}$, height $100-1000 \mathrm{~mm}$, thickness $0 \cdot 1-6 \cdot 0 \mathrm{~mm}$ and $R / t 80-1250$. The transverse shear load is applied 
as a concentrated load either at the top edge of the specimen or at a higher level in order to induce either shear or bending buckling or combined failure. Tests are conducted both at room and elevated $\left(350-500^{\circ} \mathrm{C}\right)$ temperatures. In general, it has been established that imperfections have an influence on buckling load, which is however not as significant as in the case of buckling under axial compression.

\subsection{Measurement of initial geometric imperfection}

During the early days of experiments on buckling of shells, the initial geometric imperfections were not measured and quantified, probably due to ignorance of its influence in reducing the buckling load. Systematic imperfection measurements were started in the early fifties at the US Navy David Taylor Modal Basin. In the late sixties and early seventies, complete and automated imperfection survey facilities were developed. The surveys were carried out initially on laboratory-scale models and then followed by measurements on large-scale and prototype structures. Automated systems for this purpose were developed almost simultaneously at the California Institute of Technology (CALTECH) and Stanford University in 1968. The CALTECH system uses a non-contact type transducer and is referred to as GALCIT (for Graduate Aeronautical Laboratory, California Institute of Technology) in the literature. Subsequently, similar to GALCIT, a system was established at Technion, Haifa, Israel by Singer (1979). Imperfection measurements were carried out in Imperial College, London (Dowling et al 1982) on a series of small and large stringer stiffened shells. Miller \& Grove (1986) carried out imperfection measurements on two large torispherical head models using a specially designed frame. The geometric details of the shell models were - cylinder diameter $4877 \mathrm{~mm}$, knuckle radius $829 \mathrm{~mm}$ and sphere radius $4389 \mathrm{~mm}$. Xiaoli et al (1996) carried out initial geometric imperfection measurements on silos (large size structures, dia $24 \mathrm{~m}$ and height $23 \mathrm{~m}$ ). This appears to be the largest structure on which systematic imperfection scanning has been carried out to-date. Singer \& Abramovich (1995) in their survey on development of imperfection measurement techniques stressed the importance of initial geometric imperfection and the use of the data in the design of structures for applications in the following words: If we do not know the imperfections and the boundary conditions, we cannot improve our predictions of the buckling loads, no matter how sophisticated our codes are and how large and how fast our computers become. They strongly advocate having an imperfection data bank in which the measured imperfections of all investigations are stored and used for design purposes.

\section{Present experimental studies}

\subsection{Cylindrical shell models}

Totally 24 shell models are made and grouped into three, based on their thicknesses. The three thicknesses chosen are $0.8,1.0$ and $1.25 \mathrm{~mm}$ and designated as groups I, II and III respectively. Out of 8 models in each group, 4 are earmarked for axial buckling and the remaining 4 for transverse shear buckling tests. Groups I and II are fabricated using stainless steel grade, SS316 and SS-304 is used for group III. Geometrical details of all the shell models are given in table 1 . The shell models used for axial buckling tests are numbered as AX-0i and those used for shear buckling tests are $\mathrm{SH}-0 \mathrm{i}$, where $i$ ranges from 1 to 12 . These are fabricated by rolling and TIG welding in the longitudinal direction. Stress relieving is not done, as the residual stresses arising from TIG welding are expected to be small (Teng 1996). Thick flanges 
Table 1. Geometric details of models (dimensions in $\mathrm{mm}$ ).

\begin{tabular}{|c|c|c|c|c|c|c|c|c|}
\hline \multirow[b]{2}{*}{ Group } & \multicolumn{2}{|c|}{ Model no. } & \multirow[b]{2}{*}{$t$} & \multirow[b]{2}{*}{$R$} & \multirow[b]{2}{*}{$R / t$} & \multirow[b]{2}{*}{$H$} & \multirow[b]{2}{*}{$L$} & \multirow[b]{2}{*}{$H / R$} \\
\hline & Axial & Shear & & & & & & \\
\hline \multirow{4}{*}{ I } & AX-01 & SH-01 & 0.80 & 350 & $437 \cdot 5$ & 340 & 450 & $\approx 1$ \\
\hline & AX-02 & SH-02 & 0.80 & 350 & $437 \cdot 5$ & 340 & 450 & $\approx 1$ \\
\hline & AX-03 & SH-03 & 0.80 & 350 & $437 \cdot 5$ & 340 & 450 & $\approx 1$ \\
\hline & AX-04 & SH-04 & 0.80 & 350 & $437 \cdot 5$ & 340 & 450 & $\approx 1$ \\
\hline \multirow{4}{*}{ II } & AX-05 & SH-05 & 1.00 & 350 & $350 \cdot 0$ & 340 & 450 & $\approx 1$ \\
\hline & AX-06 & SH-06 & 1.00 & 350 & $350 \cdot 0$ & 340 & 450 & $\approx 1$ \\
\hline & AX-07 & SH-07 & 1.00 & 350 & $350 \cdot 0$ & 340 & 450 & $\approx 1$ \\
\hline & AX-08 & SH-08 & 1.00 & 350 & $350 \cdot 0$ & 340 & 450 & $\approx 1$ \\
\hline \multirow{4}{*}{ III } & AX-09 & SH-09 & $1 \cdot 25$ & 350 & $280 \cdot 0$ & 340 & 450 & $\approx 1$ \\
\hline & $A X-10$ & SH-10 & 1.25 & 350 & $280 \cdot 0$ & 340 & 450 & $\approx 1$ \\
\hline & $\mathrm{AX}-11$ & SH-11 & 1.25 & 350 & $280 \cdot 0$ & 340 & 450 & $\approx 1$ \\
\hline & AX-12 & SH-12 & 1.25 & 350 & $280 \cdot 0$ & 340 & 450 & $\approx 1$ \\
\hline
\end{tabular}

machined to an accuracy of $0.01 \mathrm{~mm}$ are fitted on both ends of the models. This ensures the circularity of the shell models. The verticality of the wall and the parallelism of the flanges are checked on the surface plate. The maximum deviation observed in the axial direction is $0.9 \mathrm{~mm}$. The material properties are determined from tensile tests on coupons cut from the respective parent material.

\subsection{Imperfection measuring system}

The experimental test facility designed, fabricated and installed for the purpose of the present work is shown in figure 1 . The capacity of the test rig is $100 t$ for axial and $15 t$ for transverse shear buckling tests. The imperfection measuring system, an integral part of this facility, is of 'in-situ measurement type'. The test specimen and the system are coaxially located. Contact type transducers or linear voltage differential transformers (LVDTs) are employed to measure the imperfections. The LVDTs are mounted on special arrangements. In the case of axial buckling tests, they are located on the outside of the shell models, whereas in the case of transverse shear buckling tests, the measuring system is located inside, as demanded by the loading arrangement. Figure 2 shows the LVDT arrangement for the former and figure 3 shows the arrangement for the latter.

With reference to figure 2 , the imperfection measuring system consists of machined annular plate (4), coaxially bolted with the bottom flange of the shell model with overhang. On the overhang portion of the annular plate, 8 spherical balls are kept on the grooves, equidistant in the circumferential direction on a PCD. A ring (5) is placed around the bottom flange of the shell model with sliding tolerance and rests on the 8 balls. This enables free rotation of the ring (5) about the test specimen axis. Four LVDT holders (6) of different heights are fixed on the ring at four angular positions $\left(40^{\circ}, 90^{\circ}, 180^{\circ}\right.$ and $\left.270^{\circ}\right)$. On these holders, the LVDTs are mounted normal to the shell surface. The LVDT on the holder at $40^{\circ}$ location moves up to a distance of $95 \mathrm{~mm}$ from the bottom. Similarly, the other three holders cover the remaining 


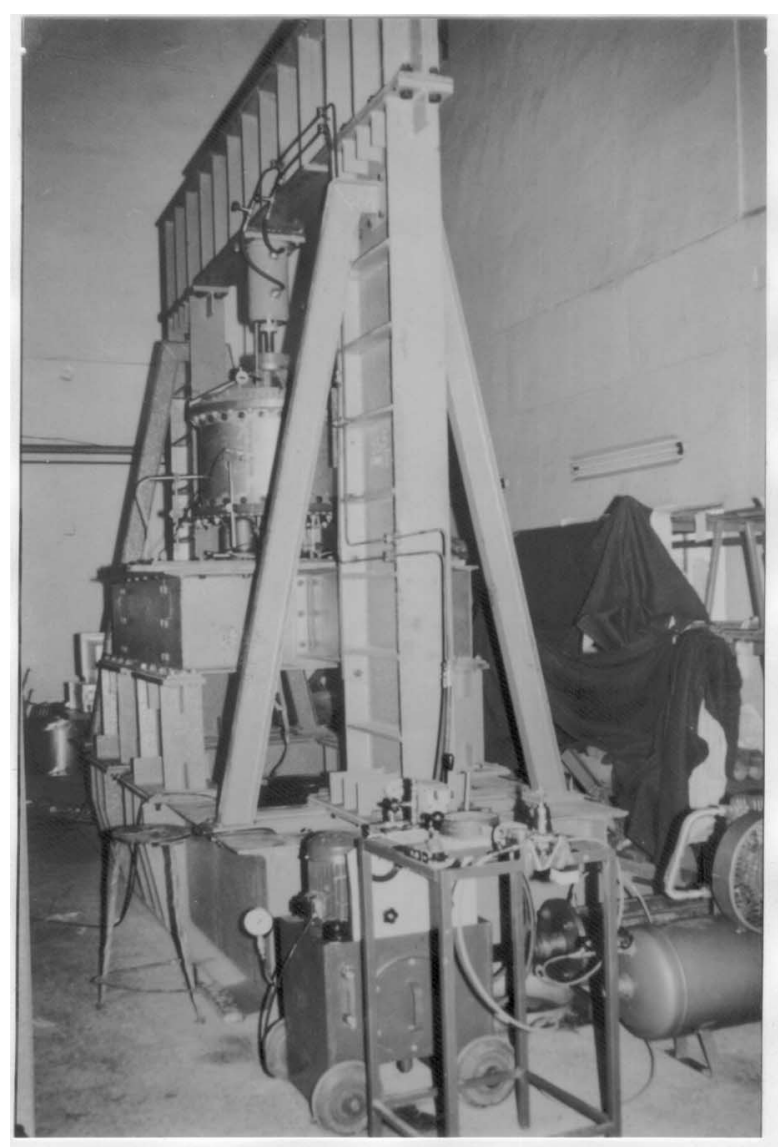

Figure 1. Photograph of the shell buckling test facility.

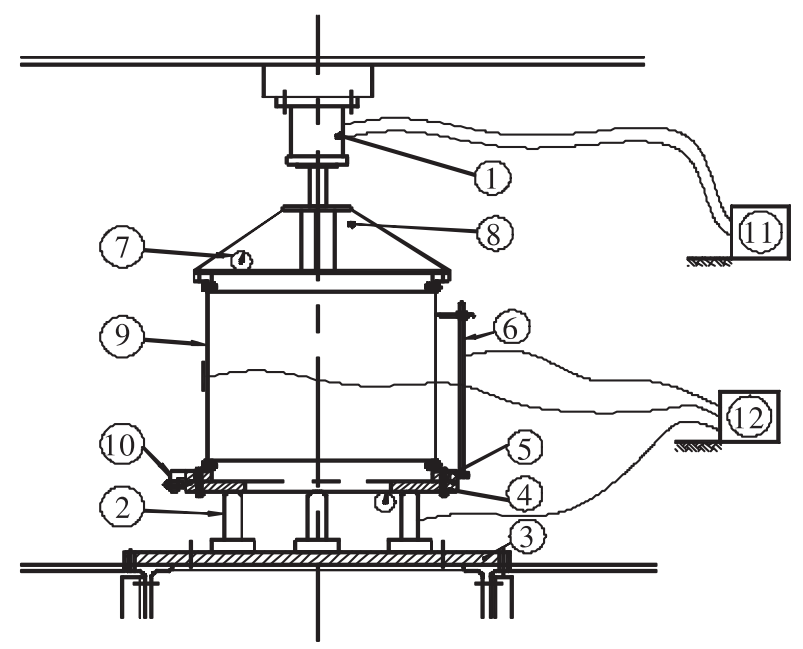
1. Hydraulic jack
2. Loadcell
3. Test Bed
4. Annular support plate
5. Rotatable ring
6. LVDT holder
7. Dial indicator
8. Loading frame
9. Shell Assembly
10. Indexing Mechanism
11. Power pack
12. Data logger
(system - 5000)
Micro measurements

Figure 2. Sketch of the shell assembly for axial buckling. 


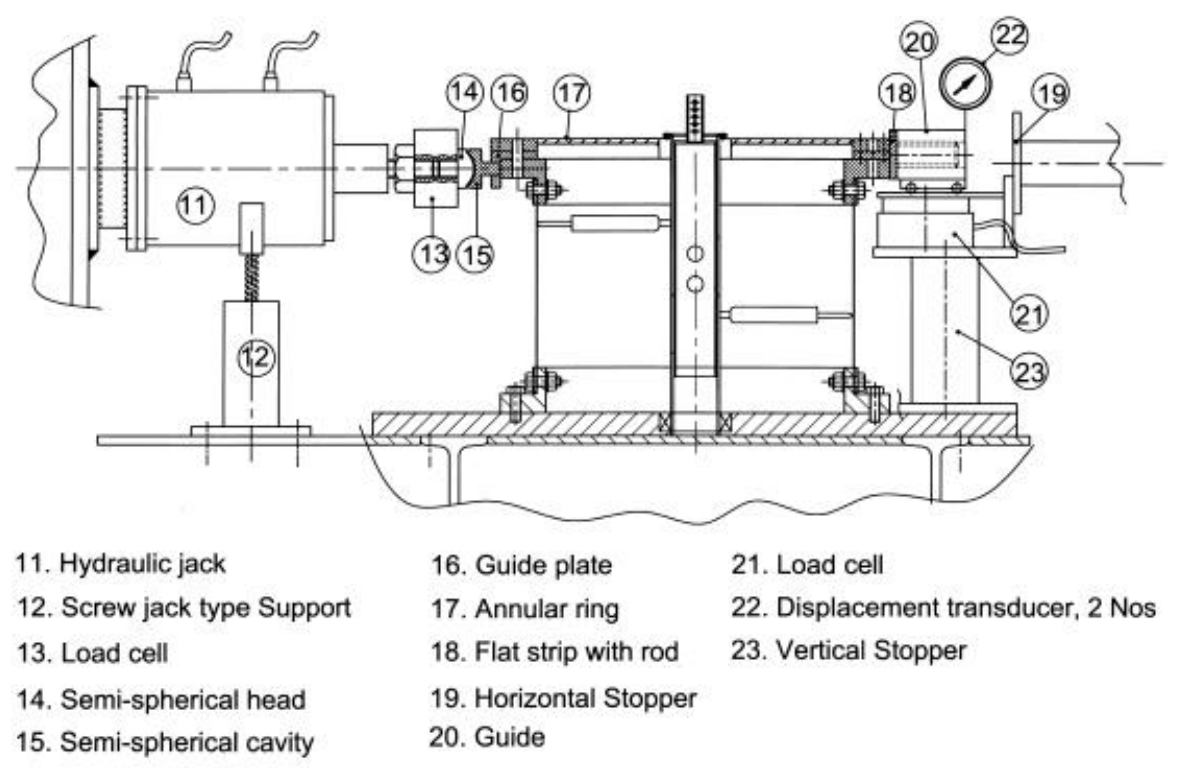

Figure 3. Sketch of transverse shear buckling.

three quarters of the specimen height. A spring loaded indexing mechanism (10) is fixed at $0^{\circ}$ location on the ring (5). The annular plate (4) has been graduated on the periphery at $5^{\circ}$ spacing. This enables imperfection measurements at intervals of $5^{\circ}$ or its multiples.

With reference to figure 3, the imperfection measuring system is kept inside the test specimen. The system consists of two coaxial tubes mounted one inside the other with sliding fit. The outer tube (O.D. $100 \mathrm{~mm}$ and $12 \mathrm{~mm}$ wall thickness) has 4 slots of $150 \mathrm{~mm}$ length, $90^{\circ}$ apart at different heights. This is press-fitted with an axial thrust bearing, which is housed in the platform (6). The inner tube is bottom-open and top-closed. Four tapped holes, $90^{\circ}$ apart are provided on the inner tube at suitable heights, matching with the slots on the outer cylinder. A rod with 4 holes at $20 \mathrm{~mm}$ spacing is screwed onto the top of the inner tube. The top end of the outer tube is closed with the guide block. LVDT holders are screwed onto the tapped holes on the inner tube. The inner tube is locked with the outer tube using a pin inserted into the holes of the rod. The lead wires of the LVDTs are taken through the inner tube and then through the central hole in the platform to the instrumentation. With this arrangement, the inner tube can only move axially within the outer tube in steps of $20 \mathrm{~mm}$ and the assembly of both the tubes can rotate through $360^{\circ}$. When the tubes are locked using the top hole in the rod, the LVDT positions correspond to the heights of 20, 100, 180 and $260 \mathrm{~mm}$ respectively from bottom. The indexing arm is clamped on the guide block. The indexing pin moves on the circular ring. After one sweep, the rod is raised by $20 \mathrm{~mm}$ and locked for the next sweep at four new levels.

\subsection{Axial buckling tests}

The details of the test setup are shown in figure 2. Maximum capacity of the test rig is $100 t$. A double acting hydraulic jack (1) is fixed at the middle of the cross-beam. A power pack (11) with air intensifier system is used to operate the hydraulic jack. The advantages of using air intensifier system are: (a) it helps in smooth application of load, (b) maintain load constant at specified level, (c) quick response during buckling. Three load cells (2) are kept $120^{\circ}$ apart on 
the bed (3). A conical loading frame (8) with flanges on both ends machined to an accuracy of $0.01 \mathrm{~mm}$ and checked for parallelism is placed on the top flange of the specimen and bolted. A guide plate is placed on the top of the conical frame with sliding fit. When the hydraulic jack is actuated, the ram moves through the central hole on the guide and rests on the top of the conical frame, to ensure the alignment of the loading system. Three pairs of dial gauges placed $120^{\circ}$ apart are used to measure the end shortening. In a pair, one gauge is kept on top and the other is at the bottom exactly below. Four pairs of strain gauges are pasted at mid height of the specimen, $90^{\circ}$ apart. In a pair, one is pasted on the inner and the other on the outer surface at the same location. Load cells, LVDTs and strain gauges are connected to the data acquisition system, M/s. Measurement Group, USA.

After mounting the specimen on the test bed as described above, firstly, initial geometric survey is carried out. LVDT readings are taken at $5^{\circ}$ intervals, at four levels 95, 170, 245 and $320 \mathrm{~mm}$ from the bottom. After each sweep of $360^{\circ}$, the LVDTs are lowered by $15 \mathrm{~mm}$ and the imperfection scan is continued. The shifting is done 4 times. In other words, LVDT readings are taken at 20 equidistant levels along the length of the specimen, which works out to 1440 locations of imperfection measurements. Subsequent to the imperfection survey, the axial load is applied in steps. The number of load steps varied from specimen to specimen with a minimum of 9 and maximum of 13. At all load steps, load cell, strain gauge and dial gauge readings are recorded. At selected load steps, LVDT scans are taken to measure the prebuckling deformation of the specimen. LVDTs are removed at about $70 \%$ of the anticipated failure load. Subsequently, finer load increments are applied till the specimen fails.

\subsection{Transverse shear buckling tests}

With reference to figure 3 , the test specimen is mounted vertical and the load is applied horizontally on the top ring (as a concentrated load in the radial direction, pointed towards the specimen centre). The hydraulic jack (11), (capacity 15t), mounted on one of the vertical columns of the test frame at the appropriate level and supported by a screw jack (12) is actuated by a power pack with air intensifier. A load cell (13) inserted between the hydraulic jack and the test specimen measures the applied load. A hemispherical ball-socket joint helps the alignment of the load. A horizontal stopper (19), located at a point, diametrically opposite of the loading point is used to limit the excessive deformation during buckling, in order to avoid any damage to the imperfection measuring system kept inside the shell model. A vertical stopper (23) is provided, with the option to restrain the axial displacement of the test specimen. Two numbers of strain gauge based displacement transducers (22) are used to measure horizontal and vertical displacements. Strain gauges are pasted at mid height both inside and outside surfaces, at plus and minus $90^{\circ}$ locations on either side of the loading plane. There are two gauges in each location with plus and minus $45^{\circ}$ orientations w.r.t. the axial generator. In some specimens, additional gauges are pasted in the hoop direction. After mounting the specimen on the test bed with all its instrumentation, firstly the imperfection survey is carried out. LVDT readings are recorded at $5^{\circ}$ intervals at four levels: $20,100,180$ and $260 \mathrm{~mm}$ in the axial direction from bottom. After each sweep of $360^{\circ}$, the LVDT positions are raised by $20 \mathrm{~mm}$. The total number of locations at which imperfections are measured works out to 1152. Subsequently, the transverse shear load is applied in steps. Load, strain and displacement gauge readings are recorded at each load increment.

The initial geometric imperfection, $\delta_{i}$ at a point is obtained using the following equation (Athiannan 2002):

$$
\delta_{i}=\Delta r_{i}+\Delta r^{\prime}-a \sin \theta_{i}-b \cos \theta_{i}
$$




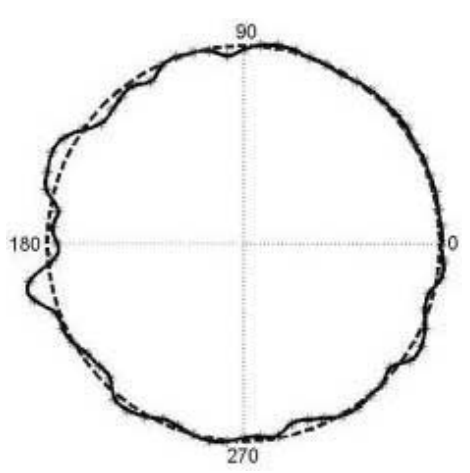

$\mathrm{Z}=155$

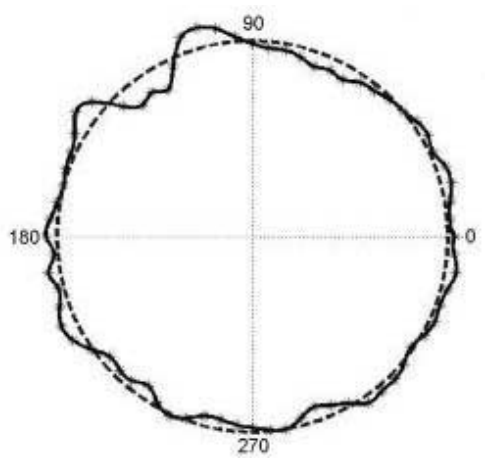

$\mathrm{Z}=215$

Figure 4. Imperfections in the circumferential direction at two levels, $Z$ from the bottom, model number AX-02: - - - - - - - perfect cross section, _ — imperfect cross section. Magnification factor 60.

where $\Delta r_{i}$-LVDT reading at location, $i, \Delta r^{\prime}=-\left(\Sigma \Delta r_{i} / n\right), a=(2 / n) \Sigma \Delta r_{i} \sin \theta_{i}, b=$ $(2 / n) \Sigma \Delta r_{i} \cos \theta_{i}$, and $n$-number of LVDT readings, equidistant around the circumference $(=72)$.

\section{Results and discussions}

\subsection{Initial geometric imperfections}

In-situ imperfection surveys are carried out on all 24 models. Complete initial geometric imperfection data for the cylindrical shell models, fabricated by rolling and welding process, collected through this study are presented in the form of figures and tables (Athiannan 2002). A few are presented here. Figure 4 shows the plots of imperfection shapes of model no. AX-02 at 2 cross sections in the axial direction, $z=155$ and $215 \mathrm{~mm}$ from bottom. The dotted lines represent the perfect geometry. The real geometrical shapes are shown by the continuous lines. The nominal radius of the model is $350 \mathrm{~mm}$. The imperfections magnified 60 times and added to the nominal radius are used in drafting the plots. This is for the purpose of clarity. Tables 2 and 3 present the imperfection values along a selected axial generator of all 24 shell models. The generator wherein the maximum imperfection, $\delta_{\max }$, lies in a model has been selected for this presentation. The circumferential locations of such generators are also indicated. From this table, it is seen that the maximum inward imperfection is equal to $-5.366 \mathrm{~mm}$ which occurs at $300^{\circ}$ on model no. SH-07 and maximum outward imperfection is equal to $5.587 \mathrm{~mm}$ which occurs at $265^{\circ}$ on model no. SH-10. The models are fabricated by rolling and seam welding process and hence the weld lines are expected to be regions of worst imperfection. However, the data in the tables belie this, as weld line does not coincide with the locations of $\delta_{\max }$ in any of the 24 models. Figure 5 shows the 3-dimensional mapping of the initial geometric imperfections of models AX- 02 and AX-12. These are the developed views of the cylindrical shells with the imperfections, from which one can see the extent of imperfection and also whether the imperfection is widespread or localized, in relation to the maximum magnitude, $\delta_{\max }$ in a model. In the study of effects of imperfections on the buckling loads, both the magnitude of imperfection $\delta_{\max }$ and the extent of imperfections need to be considered. Also, it is observed from the tables that most of the models have the maximum 


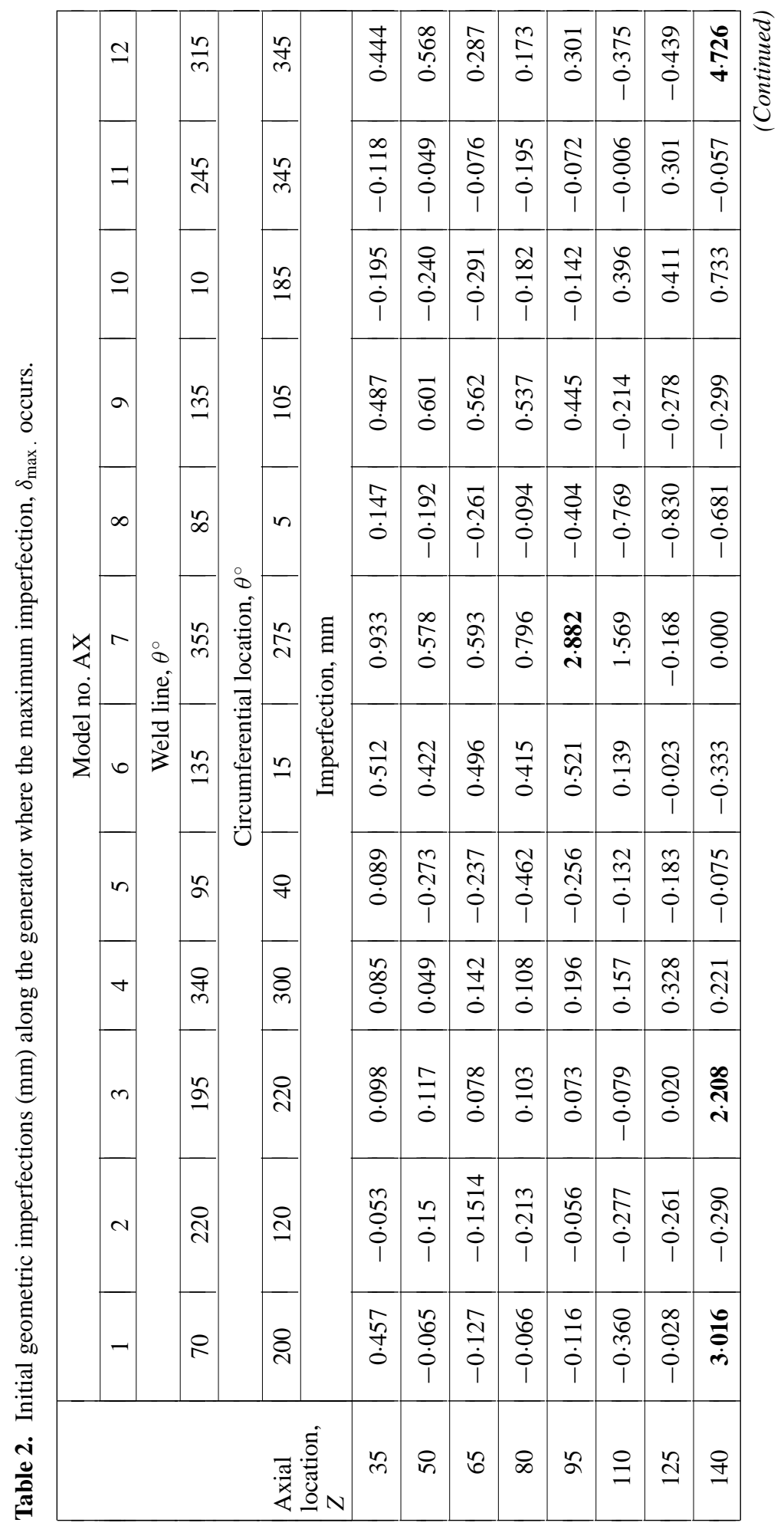




\begin{tabular}{|c|c|c|c|c|c|c|c|c|c|c|c|}
\hline 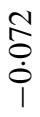 & $\frac{n}{n}$ & $\frac{n}{n}$ & $\begin{array}{l}\stackrel{8}{0} \\
\dot{0}\end{array}$ & 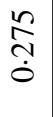 & 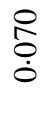 & $\frac{\tilde{n}}{\dot{0}}$ & 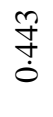 & 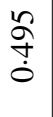 & $\begin{array}{l}\stackrel{+}{\infty} \\
\stackrel{0}{0}\end{array}$ & $\begin{array}{l}\stackrel{\overbrace{}}{0} \\
\dot{0}\end{array}$ & 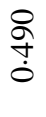 \\
\hline $\begin{array}{l}\stackrel{m}{0} \\
\dot{0}\end{array}$ & $\begin{array}{l}8 \\
0 \\
\dot{\varphi} \\
1\end{array}$ & $\begin{array}{l}0 \\
\text { oे } \\
\dot{\varphi} \\
1\end{array}$ & $\frac{\tilde{r}}{\stackrel{i}{i}}$ & $\begin{array}{l}\tilde{o} \\
\text { d }\end{array}$ & $\frac{\ddot{\infty}}{\frac{0}{0}}$ & $\begin{array}{l}0 \\
\infty \\
⿱ 亠 \\
\dot{\varphi}\end{array}$ & $\begin{array}{l}\hat{\sigma} \\
\hat{0} \\
\dot{0}\end{array}$ & $\frac{\tilde{n}}{\stackrel{f}{r}}$ & $\begin{array}{l}\text { جे } \\
\dot{0} \\
\dot{1}\end{array}$ & $\begin{array}{l}\stackrel{\infty}{f} \\
\stackrel{+}{+} \\
1\end{array}$ & $\frac{\vec{\jmath}}{\dot{0}}$ \\
\hline 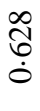 & 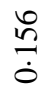 & $\frac{\stackrel{\overbrace{}}{~}}{\dot{0}}$ & $\begin{array}{l}\hat{8} \\
\stackrel{0}{0} \\
\dot{1}\end{array}$ & $\begin{array}{l}\stackrel{0}{0} \\
0 \\
\dot{0} \\
1\end{array}$ & $\begin{array}{l}\hat{o} \\
\dot{0} \\
\dot{1}\end{array}$ & $\frac{\Omega}{\stackrel{0}{i}}$ & $\begin{array}{l}\stackrel{\infty}{+} \\
\stackrel{0}{0}\end{array}$ & $\begin{array}{l}\stackrel{0}{\stackrel{+}{+}} \\
\stackrel{+}{+}\end{array}$ & $\begin{array}{l}\mathscr{\infty} \\
\stackrel{0}{0}\end{array}$ & $\underset{\text { ते }}{\vec{\oplus}}$ & 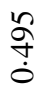 \\
\hline ஜิ & $\begin{array}{l}\stackrel{r}{o} \\
\stackrel{f}{0} \\
1\end{array}$ & $\begin{array}{l}\stackrel{\text { }}{0} \\
\dot{0}\end{array}$ & 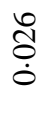 & $\begin{array}{l}\hat{n} \\
\stackrel{0}{0}\end{array}$ & $\frac{m}{\partial}$ & $\frac{\stackrel{0}{1}}{\dot{0}}$ & $\frac{\vec{I}}{\dot{0}}$ & $\begin{array}{l}\bar{\infty} \\
\infty \\
\dot{0} \\
1\end{array}$ & $\frac{\infty}{\stackrel{\infty}{\dagger}}$ & $\frac{N}{0}$ & $\begin{array}{l}\text { Oे } \\
\text { } \\
\dot{0} \\
\dot{1}\end{array}$ \\
\hline $\begin{array}{l}\stackrel{o}{+} \\
\stackrel{+}{\text { । }}\end{array}$ & $\begin{array}{l}\overline{0} \\
\dot{0} \\
1\end{array}$ & 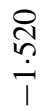 & $\begin{array}{l}\stackrel{\circ}{n} \\
\stackrel{-}{1}\end{array}$ & 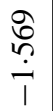 & $\frac{\stackrel{+}{0}}{\stackrel{+}{1}}$ & $\begin{array}{l}\hat{\leftrightarrow} \\
\stackrel{\leftrightarrow}{1}\end{array}$ & 今ે & $\underset{\stackrel{\sim}{\sim}}{\stackrel{\sim}{-}}$ & $\begin{array}{l}\stackrel{\infty}{\circ} \\
\stackrel{+}{-}\end{array}$ & $\vec{\sigma}$ & $\begin{array}{l}\vec{ন} \\
\infty \\
0\end{array}$ \\
\hline 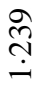 & $\stackrel{\infty}{\stackrel{\infty}{-}}$ & $\begin{array}{l}\stackrel{\infty}{+} \\
\dot{0}\end{array}$ & $\frac{2}{\dot{0}}$ & 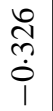 & $\begin{array}{l}\hat{6} \\
\stackrel{n}{0}\end{array}$ & $\begin{array}{l}\tilde{n} \\
\tilde{\sigma}\end{array}$ & $\begin{array}{l}\stackrel{9}{7} \\
\stackrel{+}{0} \\
1\end{array}$ & $\begin{array}{l}\stackrel{\text { I }}{+} \\
\stackrel{+}{+}\end{array}$ & $\begin{array}{l}\bar{\sigma} \\
\stackrel{\oplus}{0} \\
1\end{array}$ & $\frac{\text { I }}{\dot{0}}$ & 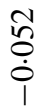 \\
\hline$\frac{\vec{N}}{\grave{\dagger}}$ & $\begin{array}{l}\overrightarrow{\widetilde{N}} \\
\dot{0}\end{array}$ & $\begin{array}{l}\stackrel{+}{+} \\
\dot{0}\end{array}$ & 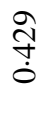 & $\begin{array}{l}\stackrel{n}{o} \\
\dot{0}\end{array}$ & $\begin{array}{l}\stackrel{\circ}{\circ} \\
\stackrel{0}{0}\end{array}$ & $\underset{\text { i }}{\stackrel{ \pm}{\mathbf{d}}}$ & $\begin{array}{l}0 \\
\infty \\
\infty \\
\dot{\varphi}\end{array}$ & $\frac{\infty}{\stackrel{\leftrightarrow}{\dagger}}$ & $\begin{array}{l}\text { त̂ } \\
\dot{0} \\
\stackrel{1}{1}\end{array}$ & $\frac{\overrightarrow{0}}{\dot{0}}$ & 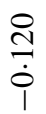 \\
\hline$\stackrel{丷}{\dot{i}}$ & $\frac{\tilde{m}}{\dot{m}}$ & $\stackrel{n}{\tilde{0}}$ & $\stackrel{\infty}{\stackrel{\oplus}{0}}$ & \begin{tabular}{l}
0 \\
\multirow{2}{+}{} \\
$\dot{0}$ \\
0
\end{tabular} & $\frac{8}{0}$ & $\begin{array}{l}\infty \\
\infty \\
\dot{0} \\
1\end{array}$ & $\frac{\hat{N}}{\dot{0}}$ & $\frac{\dot{J}}{\overrightarrow{0}}$ & $\begin{array}{l}\hat{8} \\
0 \\
\dot{0} \\
1\end{array}$ & $\stackrel{\bar{o}}{\dot{0}}$ & $\begin{array}{l}\stackrel{n}{\hat{o}} \\
\dot{0} \\
\dot{1}\end{array}$ \\
\hline $\begin{array}{l}\frac{d}{0} \\
\dot{0}\end{array}$ & $\begin{array}{l}\stackrel{0}{0} \\
\stackrel{0}{+}\end{array}$ & $\frac{\tilde{m}}{\dot{0}}$ & $\frac{\mathscr{n}}{\stackrel{0}{0}}$ & $\begin{array}{l}\bar{\sigma} \\
0 \\
\dot{0} \\
1\end{array}$ & $\begin{array}{l}0 \\
0 \\
\dot{0} \\
1\end{array}$ & 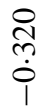 & $\frac{\stackrel{m}{\oplus}}{\dot{0}}$ & $\begin{array}{l}\stackrel{+}{0} \\
\stackrel{0}{1}\end{array}$ & $\begin{array}{l}\stackrel{g}{\circ} \\
\dot{0}\end{array}$ & 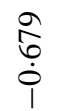 & $\frac{m}{\dot{m}}$ \\
\hline ஸे & $\frac{\vec{m}}{\dot{0}}$ & $\frac{\stackrel{g}{+}}{\dot{0}}$ & $\stackrel{n}{\frac{n}{0}}$ & $\frac{n}{\frac{n}{0}}$ & $\begin{array}{l}\stackrel{\imath}{1} \\
\text { }\end{array}$ & $\begin{array}{l}\stackrel{+}{0} \\
\text { ஸे }\end{array}$ & $\begin{array}{l}+ \\
\stackrel{0}{0} \\
\stackrel{0}{0}\end{array}$ & $\frac{n}{0}$ & $\begin{array}{l}\stackrel{\overbrace{}}{N} \\
\dot{0}\end{array}$ & $\frac{\tilde{2}}{\dot{0}}$ & 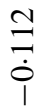 \\
\hline 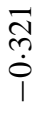 & $\begin{array}{l}\text { Jे } \\
\dot{\varphi}\end{array}$ & $\begin{array}{l}\stackrel{2}{~} \\
\dot{i}\end{array}$ & $\begin{array}{l}\bar{n} \\
\dot{i} \\
\dot{i}\end{array}$ & $\begin{array}{l}0 \\
\infty \\
\dot{0} \\
\dot{1}\end{array}$ & $\stackrel{\stackrel{\oplus}{\oplus}}{\stackrel{\oplus}{\dagger}}$ & $\frac{\underset{\Delta}{\Delta}}{\text { I }}$ & $\begin{array}{l}\infty \\
\stackrel{0}{0} \\
\dot{0}\end{array}$ & $\begin{array}{l}\infty \\
\stackrel{8}{o} \\
\dot{\varphi}\end{array}$ & $\begin{array}{l}\text { fo } \\
\dot{0} \\
\dot{1}\end{array}$ & $\begin{array}{l}\stackrel{N}{0} \\
\dot{0} \\
1\end{array}$ & 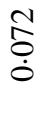 \\
\hline $\begin{array}{l}0 \\
\stackrel{0}{0} \\
\stackrel{0}{0} \\
1\end{array}$ & $\stackrel{\vec{n}}{\frac{n}{0}}$ & $\begin{array}{l}\infty \\
\stackrel{0}{0} \\
\stackrel{0}{1} \\
1\end{array}$ & $\frac{\partial}{\dot{0}}$ & $\underset{\stackrel{J}{J}}{\stackrel{J}{\Delta}}$ & $\begin{array}{l}\overrightarrow{7} \\
\dot{+} \\
i\end{array}$ & $\begin{array}{l}\overrightarrow{\stackrel{\sigma}{ }} \\
\text { }\end{array}$ & $\underset{\stackrel{\overbrace{}}{0}}{0}$ & $\stackrel{\mathscr{o}}{\stackrel{0}{0}}$ & $\frac{n}{\tilde{0}}$ & $\underset{+}{\stackrel{+}{0}}$ & $\frac{\stackrel{\infty}{+}}{0}$ \\
\hline$n$ & $\stackrel{P}{I}$ & $\infty$ & 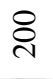 & $\frac{n}{\sim}$ & હે & $\stackrel{n}{\sim}$ & $\underset{\sim}{\stackrel{8}{0}}$ & $\stackrel{n}{\stackrel{n}{v}}$ & ঐి & ?ి & ָి \\
\hline
\end{tabular}




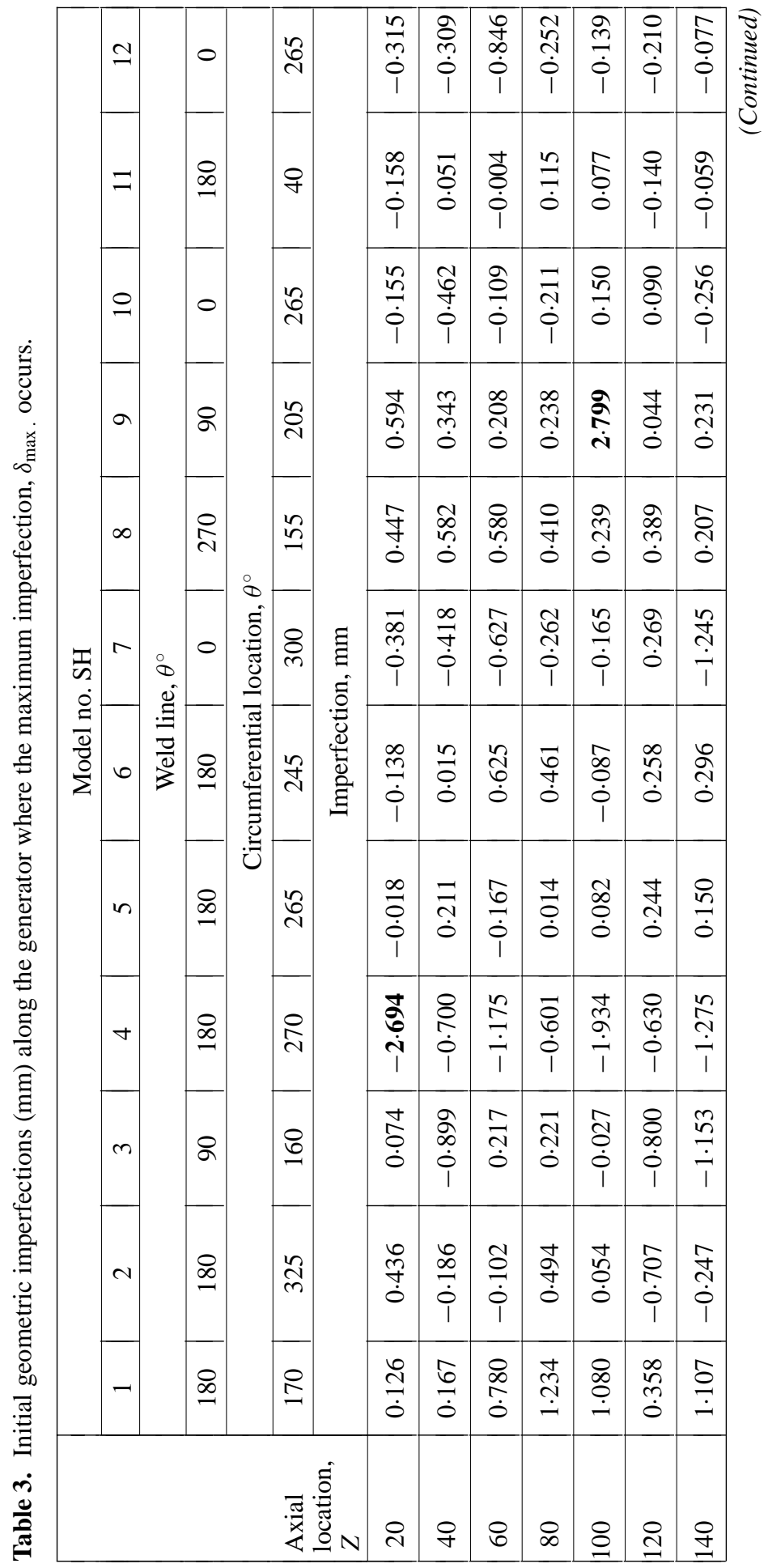


Buckling of cylindrical shells under axial compression and transverse shear 105

\begin{tabular}{|c|c|c|c|c|c|c|c|c|}
\hline 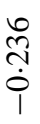 & $\begin{array}{l}\mathscr{1} \\
\stackrel{0}{0} \\
\dot{0}\end{array}$ & $\begin{array}{l}\text { ñ } \\
\dot{0}\end{array}$ & $\underset{\dot{m}}{\ddot{\infty}}$ & $\begin{array}{l}n \\
n \\
n \\
0\end{array}$ & $\begin{array}{l}\overrightarrow{\widetilde{Y}} \\
\stackrel{+}{\dagger} \\
\stackrel{1}{0}\end{array}$ & $\begin{array}{l}n \\
\infty \\
0 \\
\dot{0}\end{array}$ & 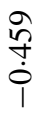 & $\begin{array}{l}\text { ô } \\
\dot{\phi} \\
\dot{i}\end{array}$ \\
\hline $\begin{array}{c}\text { ֻூ } \\
\dot{\varphi} \\
\dot{1}\end{array}$ & $\frac{N}{0}$ & $\begin{array}{l}\bar{n} \\
\stackrel{0}{0}\end{array}$ & $\frac{8}{\dot{0}}$ & $\frac{\tilde{n}}{\dot{m}}$ & $\underset{\sim}{\stackrel{\sim}{\sim}}$ & $\begin{array}{l}\tilde{n} \\
\tilde{n} \\
0\end{array}$ & $\frac{\infty}{0}$ & $\frac{n}{0}$ \\
\hline$\frac{\stackrel{\infty}{+}}{\dot{\varphi}}$ & $\begin{array}{l}\stackrel{2}{\infty} \\
\dot{\sim} \\
i\end{array}$ & $\begin{array}{l}\stackrel{2}{\infty} \\
\infty \\
\dot{\gamma} \\
1\end{array}$ & $\begin{array}{l}\hat{\infty} \\
i \infty \\
\text { in }\end{array}$ & $\begin{array}{l}\stackrel{+}{+} \\
\stackrel{m}{0}\end{array}$ & $\frac{n}{\infty}$ & $\begin{array}{l}0 \\
0 \\
0 \\
\dot{0} \\
1\end{array}$ & $\begin{array}{l}\infty \\
8 \\
\dot{0}\end{array}$ & $\stackrel{m}{0}_{i}^{+}$ \\
\hline 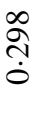 & $\overrightarrow{0}$ & $\begin{array}{l}\stackrel{\circ}{\circ} \\
\dot{\varphi}\end{array}$ & $\begin{array}{l}\hat{\overbrace{}} \\
\dot{0}\end{array}$ & 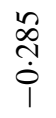 & $\frac{\infty}{\infty}$ & $\frac{n}{\frac{n}{0}}$ & $\begin{array}{l}\bar{g} \\
\dot{i}\end{array}$ & $\frac{\pi}{0}$ \\
\hline$\frac{\text { In }}{\dot{0}}$ & $\frac{2}{\frac{1}{0}}$ & $\begin{array}{l}\bar{\sigma} \\
\tilde{0}\end{array}$ & $\begin{array}{l}\hat{\sigma} \\
\dot{0}\end{array}$ & $\begin{array}{l}\text { గ్t } \\
\dot{0}\end{array}$ & $\begin{array}{l}\stackrel{n}{\prime} \\
0\end{array}$ & 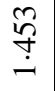 & 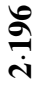 & $\frac{\partial}{0}$ \\
\hline$\frac{\grave{ }}{0}$ & $\frac{i}{\frac{n}{0}}$ & $\frac{g}{\dot{0}}$ & $\begin{array}{l}\text { J } \\
\stackrel{0}{0} \\
\dot{0}\end{array}$ & $\begin{array}{l}\dot{0} \\
\dot{m} \\
\dot{1}\end{array}$ & $\frac{\vec{m}}{\dot{0}}$ & $\begin{array}{l}0 \\
0 \\
\stackrel{0}{0}\end{array}$ & $\stackrel{\overrightarrow{5}}{\stackrel{+}{\leftrightarrow}}$ & 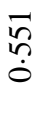 \\
\hline $\begin{array}{l}\stackrel{\vartheta}{\hat{~}} \\
\grave{0}\end{array}$ & $\begin{array}{l}\frac{J}{0} \\
\stackrel{0}{\dagger}\end{array}$ & $\begin{array}{l}\infty \\
\stackrel{0}{0} \\
\dot{0} \\
1\end{array}$ & $\stackrel{\vartheta}{\stackrel{\rho}{-}}$ & $\frac{\mathfrak{d}}{\dot{0}}$ & $\frac{m}{\overrightarrow{0}}$ & 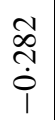 & 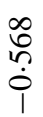 & $\hat{\dot{\phi}}$ \\
\hline$\frac{\grave{1}}{\grave{0}}$ & $\begin{array}{l}\stackrel{+}{8} \\
\dot{0}\end{array}$ & $\begin{array}{l}8 \\
8 \\
\vdots \\
\dot{0}\end{array}$ & 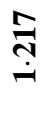 & $\begin{array}{l}\overrightarrow{\hat{\jmath}} \\
\dot{0}\end{array}$ & $\begin{array}{l}\vec{J} \\
\dot{0}\end{array}$ & $\frac{\hat{\Sigma}}{\dot{0}}$ & 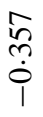 & $\begin{array}{l}8 \\
\dot{0} \\
\dot{1}\end{array}$ \\
\hline $\begin{array}{l}\underset{+}{+} \\
\stackrel{i}{i}\end{array}$ & $\begin{array}{l}\stackrel{2}{\hat{े}} \\
\stackrel{i}{i}\end{array}$ & $\frac{8}{\stackrel{8}{\dot{i}}}$ & $\begin{array}{l}\vec{\sigma} \\
\stackrel{-}{-}\end{array}$ & $\begin{array}{l}\hat{\hat{S}} \\
\dot{0}\end{array}$ & $\begin{array}{l}\text { ల్ } \\
\stackrel{6}{0} \\
\dot{0}\end{array}$ & $\begin{array}{l}\vec{n} \\
\tilde{0}\end{array}$ & $\frac{\mathfrak{y}}{\dot{0}}$ & $\begin{array}{l}\text { t } \\
\dot{0}\end{array}$ \\
\hline $\begin{array}{l}n \\
\ddot{0} \\
\dot{0} \\
1\end{array}$ & $\begin{array}{l}\stackrel{+}{+} \\
\stackrel{+}{+}\end{array}$ & $\stackrel{8}{\stackrel{8}{-}}$ & $\begin{array}{l}\text { Dे } \\
\text { Oे } \\
\dot{0}\end{array}$ & $\begin{array}{l}\text { I } \\
\dot{0}\end{array}$ & $\begin{array}{l}0 \\
\stackrel{+}{+} \\
\dot{0} \\
1\end{array}$ & $\begin{array}{l}\overrightarrow{8} \\
\dot{\theta}\end{array}$ & 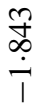 & $\begin{array}{l}\infty \\
\infty \\
\dot{\varphi} \\
1\end{array}$ \\
\hline$\frac{\Xi}{\overrightarrow{0}}$ & $\begin{array}{l}\text { fे } \\
\text { ’ } \\
0\end{array}$ & $\begin{array}{l}\infty \\
\stackrel{\infty}{0} \\
\dot{0}\end{array}$ & 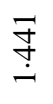 & 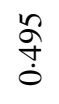 & $\begin{array}{c}\underset{ٍ}{\tilde{j}} \\
\dot{\dot{j}}\end{array}$ & $\begin{array}{l}\infty \\
\stackrel{\sim}{\sim} \\
\dot{\sim}\end{array}$ & $\frac{m}{\alpha}$ & $\stackrel{\infty}{\stackrel{\infty}{\sim}}$ \\
\hline$\frac{\infty}{\vec{\forall}}$ & $\begin{array}{l}\stackrel{\leftrightarrow}{n} \\
\stackrel{\sim}{\sim}\end{array}$ & $\begin{array}{l}\infty \\
\stackrel{\infty}{\dot{\sim}}\end{array}$ & 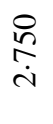 & $\begin{array}{l}\tilde{\infty} \\
\infty \\
\dot{\infty}\end{array}$ & $\begin{array}{l}\stackrel{n}{o} \\
\dot{f} \\
\dot{\imath}\end{array}$ & $\stackrel{\text { }}{\stackrel{\dagger}{।}}$ & 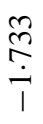 & 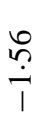 \\
\hline$\stackrel{8}{8}$ & $\stackrel{\infty}{=}$ & 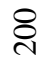 & 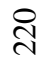 & 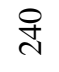 & $\stackrel{8}{\circ}$ & $\underset{\sim}{\stackrel{D}{N}}$ & ষ্ণ & ָె \\
\hline
\end{tabular}



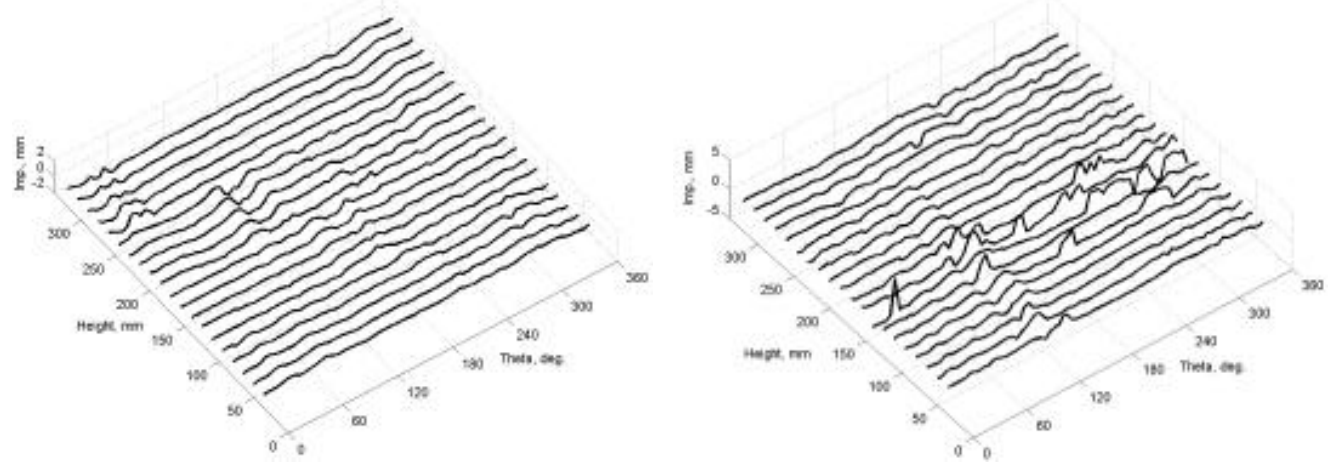

Figure 5. 3-D mapping of initial geometric imperfection, model no: AX-02 and AX-12. (b) Model no. AX-02 $\delta_{\max }=-1.034 \mathrm{~mm}$ (f) Model no. AX-12 $\delta_{\max }=4.726 \mathrm{~mm}$.

imperfection, $\delta_{\max }<3 \mathrm{~mm}$ except for a few. In addition, it is observed that the imperfection amplitudes as multiples of wall thickness decrease as the wall thickness increases.

\subsection{Buckling loads}

4.2a Axial buckling: Load cell, strain gauge and dial gauge readings (for end shortening) are recorded at each increment of loading till the specimen fails. Just before failure, the formation of lobes is observed visually which is followed immediately by a thud (dull sound). Figure 6 shows the load vs. end shortening for model no. AX-01. For measuring the end shortening, three pairs of dial gauges, $120^{\circ}$ apart are used. In a pair, one is kept at top and the other at bottom directly below. The difference between the readings of a pair gives the end shortening. The average of the three pairs is used to plot this graph. The dial gauges are not removed till the specimen fails. However, the gauge readings become meaningless once the specimen

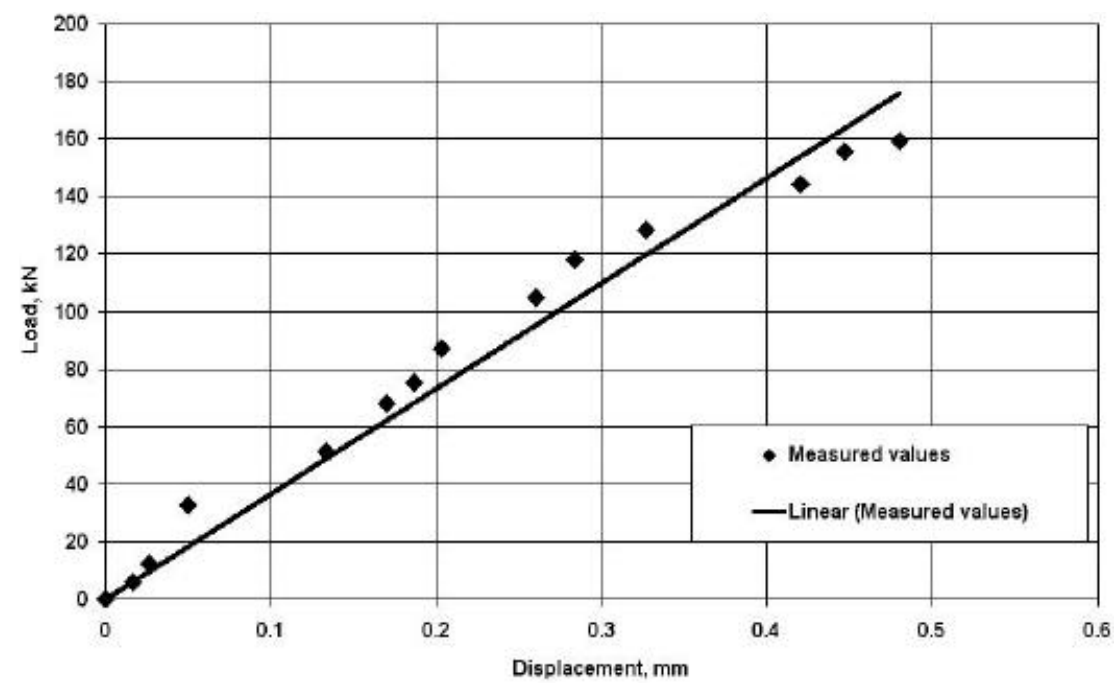

Figure 6. Experimental load vs. end shortening, model no. AX-01. 
Table 4. Axial buckling: Experimental and numerical loads.

\begin{tabular}{|c|c|c|c|c|c|c|c|c|c|c|}
\hline \multirow{3}{*}{ 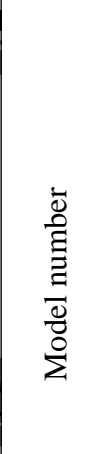 } & \multirow{3}{*}{ 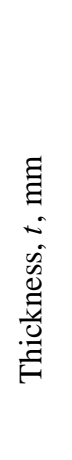 } & \multicolumn{9}{|c|}{ Buckling load, kN } \\
\hline & & 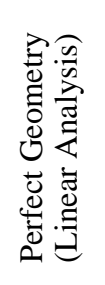 & 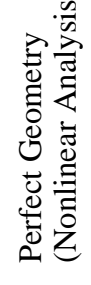 & 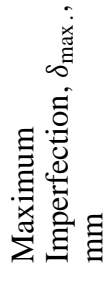 & 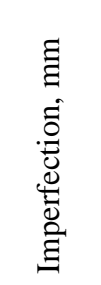 & 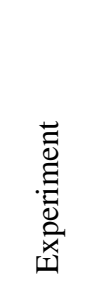 & 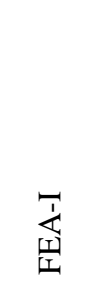 & 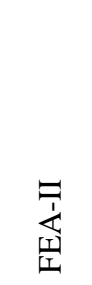 & 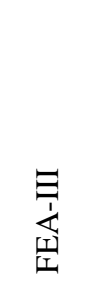 & 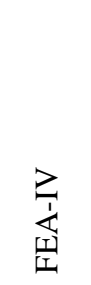 \\
\hline & & & & & $\delta_{\mathrm{RMSG}}$ & & & & & \\
\hline AX-01 & \multirow{4}{*}{$0 \cdot 8$} & \multirow{4}{*}{$486 \cdot 0$} & \multirow{4}{*}{$424 \cdot 0$} & $3 \cdot 02$ & $0 \cdot 83$ & $163 \cdot 0$ & $143 \cdot 0$ & $129 \cdot 0$ & $177 \cdot 4$ & $135 \cdot 3$ \\
\hline $\mathrm{AX}-02$ & & & & 1.03 & 0.43 & 135.9 & 179.0 & 161.5 & 247.0 & $178 \cdot 2$ \\
\hline $\mathrm{AX}-03$ & & & & $2 \cdot 20$ & $0 \cdot 54$ & $140 \cdot 6$ & $166 \cdot 0$ & $151 \cdot 0$ & $224 \cdot 2$ & $167 \cdot 0$ \\
\hline AX-04 & & & & $4 \cdot 60$ & 1.05 & $140 \cdot 0$ & $168 \cdot 0$ & $119 \cdot 0$ & $150 \cdot 9$ & $116 \cdot 6$ \\
\hline AX-05 & \multirow{4}{*}{$1 \cdot 0$} & \multirow{4}{*}{$799 \cdot 7$} & \multirow{4}{*}{$577 \cdot 7$} & $3 \cdot 30$ & $0 \cdot 84$ & $242 \cdot 2$ & $197 \cdot 0$ & $283 \cdot 2$ & $303 \cdot 0$ & $209 \cdot 2$ \\
\hline AX-06 & & & & $2 \cdot 01$ & 0.74 & $232 \cdot 5$ & $270 \cdot 0$ & $288 \cdot 0$ & 324.9 & $226 \cdot 6$ \\
\hline AX-07 & & & & $2 \cdot 88$ & $1 \cdot 08$ & $219 \cdot 5$ & $229 \cdot 0$ & $254 \cdot 4$ & 254.9 & $178 \cdot 6$ \\
\hline AX-08 & & & & $1 \cdot 86$ & 1.08 & $247 \cdot 1$ & $263 \cdot 0$ & $254 \cdot 4$ & 254.9 & $178 \cdot 6$ \\
\hline AX-09 & \multirow{4}{*}{1.25} & \multirow{4}{*}{$1185 \cdot 4$} & \multirow{4}{*}{$701 \cdot 1$} & 3.03 & $1 \cdot 54$ & $320 \cdot 1$ & $398 \cdot 0$ & $360 \cdot 0$ & $344 \cdot 8$ & $210 \cdot 1$ \\
\hline$A X-10$ & & & & $1 \cdot 32$ & 0.45 & $321 \cdot 0$ & $398 \cdot 9$ & $478 \cdot 8$ & $604 \cdot 3$ & $402 \cdot 6$ \\
\hline $\mathrm{AX}-11$ & & & & $3 \cdot 70$ & 0.93 & $309 \cdot 8$ & $421 \cdot 6$ & $388 \cdot 0$ & $484 \cdot 0$ & $277 \cdot 2$ \\
\hline AX-12 & & & & $4 \cdot 70$ & $1 \cdot 11$ & 286.7 & 284.0 & 376.8 & $443 \cdot 0$ & 253.0 \\
\hline
\end{tabular}

collapses. The experimental buckling loads for all the models are presented in table 4 . The results are given in three groups, based on the wall thickness: $t=0.8,1.0$ and $1.25 \mathrm{~mm}$ with the corresponding $R / t$ ratios of 437.5, 350 and 280. As seen from the table, the buckling loads vary from specimen to specimen within the group. Considering the imperfections and the corresponding failure loads in a group, it is expected that the load will be inversely proportional to the magnitude of imperfection. However, this trend is not exhibited in group I $(t=0.8 \mathrm{~mm})$. For model no. AX-02, $\delta_{\max }$ is the lowest $(=1.03 \mathrm{~mm})$ and the buckling load is also the lowest $(=135.9 \mathrm{kN})$ which is contrary to the expectation. In groups II and III, the expected trend is again seen, except in one case (AX-05). However, it is observed that the extent of imperfection (the percentage area over which the imperfections are present) seems to influence the buckling load; the larger the area, the lower the load. Figure 7 is the 


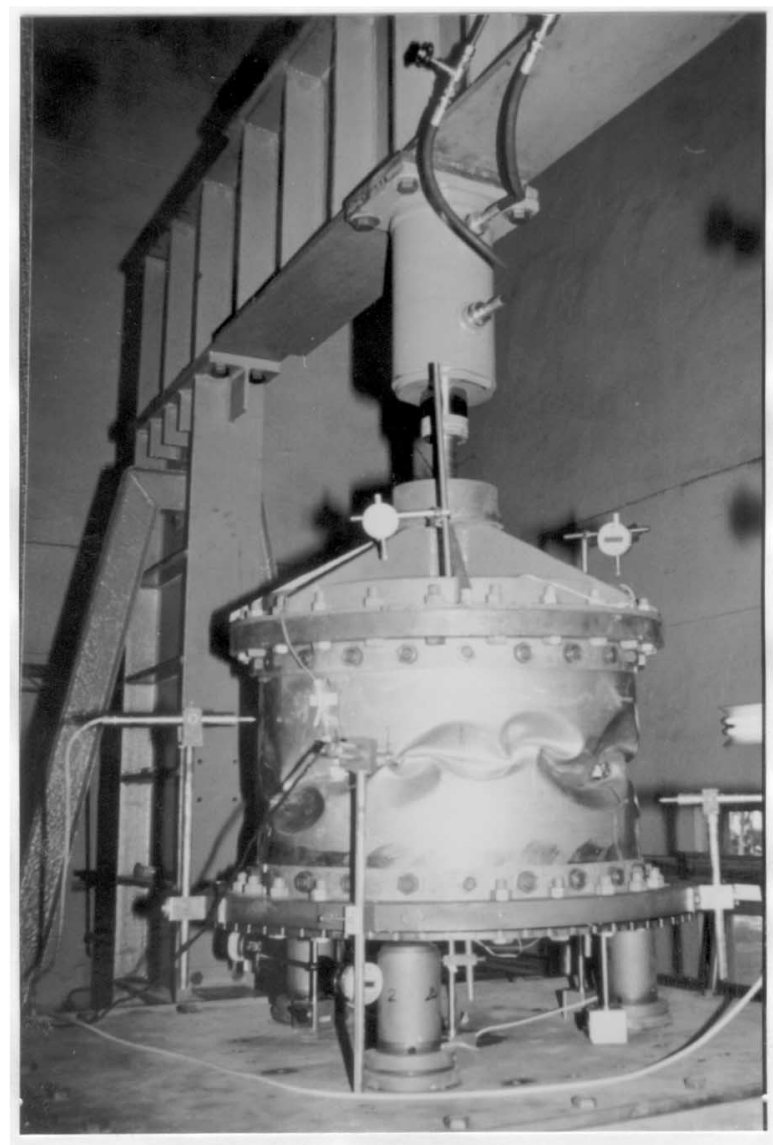

Figure 7. Photograph of buckled shell - axial compression, model no. $\mathrm{AX}-02$.

photograph of the buckled specimen, AX-02. Figure 8 shows the plot of load vs. strain for model no. AX-06. It is observed that in a pair of strain gauges, initially the nature of strain is the same, with a small difference indicating predominantly membrane prebuckling state of stress. The strains increase linearly with load. As the load approaches the failure level, the nature of strain in a pair changes suddenly, indicating switch over to the bending state of stress. At the time of buckling, all the gauges experience sudden increase in strain values and the curves turn vertically up or down. The arrow indicates the buckling load. This helps to pinpoint the failure load experimentally.

Buckling loads are also obtained through FEM. The FE modelling of the shell buckling under axial load with initial geometric imperfections has been carried out in four ways: (i) geometry with real imperfection, FEA-I, (ii) geometry with axisymmetric imperfection, FEAII (circumferential wave number, $n=0$ ), (iii) geometry with nonaxisymmetric imperfection, FEA-III $(n>0)$ and (iv) axisymmetric imperfect geometry using axisymmetric shell element, FEA-IV. The doubly curved shell element, S8R5 of ABAQUS (ABACUS FE) is employed in the first three models and 3-node axisymmetric shell element, SAX2 (ABAQUS) is employed in FEA-IV. The full shell is taken for modelling in the case of FEA-I and FEA-II whereas a segment corresponding to half-wavelength (subtended angle, $\alpha=\pi / n$ ) in the circumferential and half length in the axial directions are taken for FEA-III modelling. The FE mesh of FEAI and FEA-II consist of 120 elements in the circumferential and 22 elements in the axial 


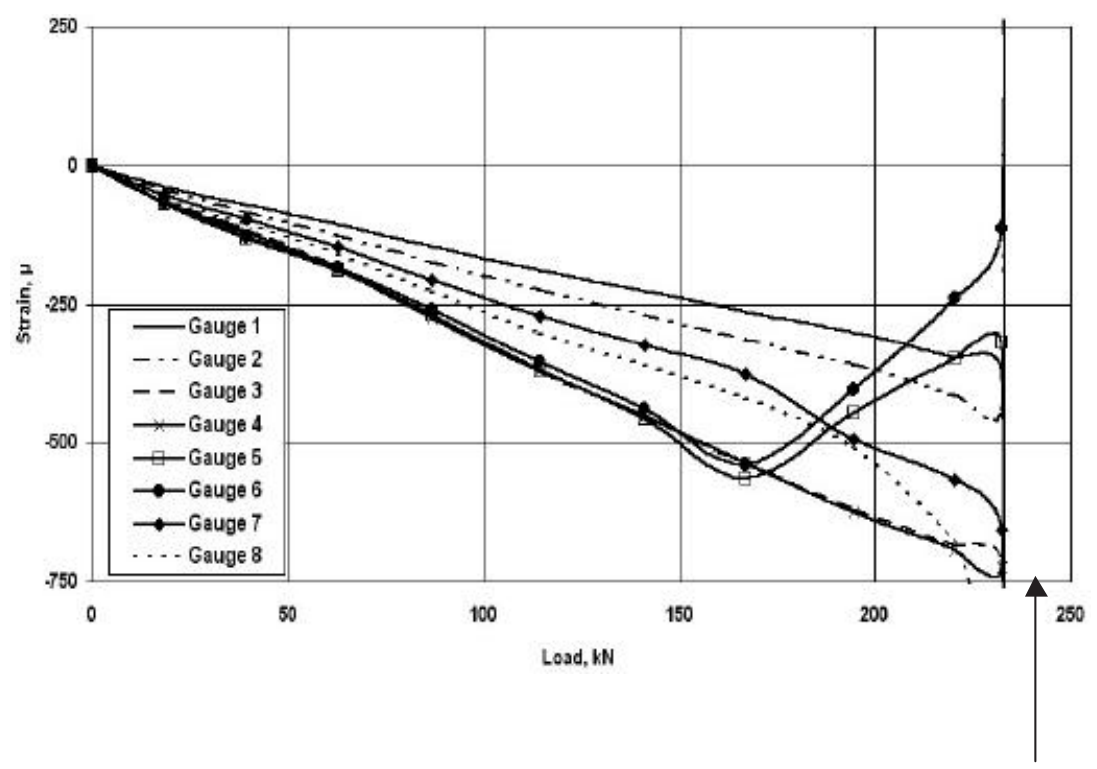

Figure 8. Experimental load vs. strain - axial compression, model no. AX-06 (arrow indicates the buckling load).

directions. The mesh of FEA-III consists of $6 \times 10$ (circumferential $\times$ axial) or $8 \times 10$ depending on the thickness. The mesh of FEA-IV consists of 22 elements only. In the case of FEA-I, the imperfect model is obtained by perturbing the radial coordinates of all nodes of the perfect shell using the corresponding nodal imperfections. FEA-II, FEA-III and FEA-IV are idealized imperfection models. The critical eigen modes of the perfect shells are renormalised using the RMS (root mean square) values of the measured imperfections of nodes lying along an axial generator. Imperfections measured experimentally result in 72 RMS values for a specific test specimen. Among the 72 RMS values, the maximum is taken to renormalise the eigen mode to obtain the imperfect geometry. General nonlinear options available in ABAQUS have been utilised in the solution procedure. Full details of the FE modelling are available in Athiannan (2002). The numerical buckling loads obtained from the FE modelling are also presented in the last four columns of table 4. From a comparison of experimental buckling loads with the numerically obtained values, the following observations are made. In general, the numerical values predicted by the FEA-IV are lower than the experimental loads, whereas model FEA-I and FEA-II predict values slightly higher than that of experimental buckling loads. On the other hand, FEA-III predicts much higher loads, in spite of the fact that the same magnitude of imperfections has been imposed in all the three models. This is mainly due to the difference in the kind of imperfection shapes imposed. It is concluded that the finite element modelling of imperfect shell using axisymmetric shell element, FEA-IV is conservative and hence it is more appropriate for design purposes.

4.2b Shear buckling: Load, strains and horizontal deformation are recorded at each load step till the failure of the specimen occurs. Just before failure, wrinkles (buckling lobes) are formed at an angle of $45^{\circ}$ orientation with reference to the axial generator on both the sides of the line of action of transverse shear loading. The buckling phenomenon is slow and steady, unlike 
Table 5. Shear buckling: experimental and numerical loads.

\begin{tabular}{|c|c|c|c|c|c|c|c|}
\hline \multirow[b]{2}{*}{ 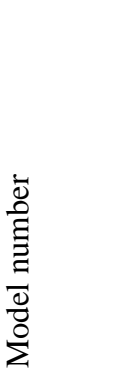 } & \multirow[b]{2}{*}{ 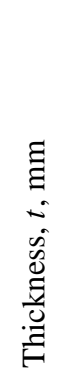 } & \multicolumn{6}{|c|}{ Buckling load, kN } \\
\hline & & 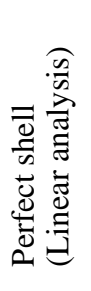 & 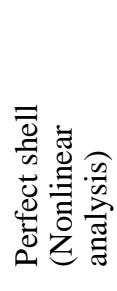 & 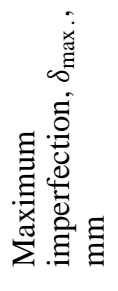 & 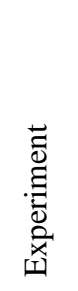 & $\begin{array}{l}\bar{y} \\
\text { II } \\
\text { In }\end{array}$ & $\begin{array}{l}= \\
\text { ஸे } \\
\text { त̂t }\end{array}$ \\
\hline SH-01 & \multirow{4}{*}{$0 \cdot 8$} & \multirow{4}{*}{$66 \cdot 8$} & \multirow{4}{*}{$63 \cdot 7$} & $3 \cdot 9$ & $45 \cdot 5$ & $62 \cdot 1$ & 59.8 \\
\hline $\mathrm{SH}-02$ & & & & $3 \cdot 0$ & $54 \cdot 4$ & 61.4 & $60 \cdot 2$ \\
\hline $\mathrm{SH}-03^{*}$ & & & & $4 \cdot 0$ & 33.4 & $63 \cdot 6$ & 62.4 \\
\hline $\mathrm{SH}-04^{*}$ & & & & $2 \cdot 7$ & 32.4 & $63 \cdot 8$ & $62 \cdot 8$ \\
\hline SH-05 & \multirow{4}{*}{$1 \cdot 0$} & \multirow{4}{*}{$106 \cdot 0$} & \multirow{4}{*}{$101 \cdot 3$} & $1 \cdot 2$ & 57.4 & $102 \cdot 3$ & $96 \cdot 8$ \\
\hline SH-06 & & & & $1 \cdot 3$ & $69 \cdot 0$ & 99.6 & $96 \cdot 7$ \\
\hline $\mathrm{SH}-07^{*}$ & & & & 5.4 & $69 \cdot 0$ & $105 \cdot 4$ & $94 \cdot 1$ \\
\hline SH-08* & & & & $2 \cdot 2$ & $50 \cdot 0$ & $100 \cdot 1$ & $100 \cdot 0$ \\
\hline SH-09 & \multirow{4}{*}{1.25} & \multirow{4}{*}{$167 \cdot 6$} & \multirow{4}{*}{$151 \cdot 0$} & $2 \cdot 8$ & 98.4 & $132 \cdot 8$ & $128 \cdot 6$ \\
\hline SH-10 & & & & $5 \cdot 6$ & 99.0 & $130 \cdot 1$ & $122 \cdot 8$ \\
\hline SH-11* & & & & $2 \cdot 2$ & $72 \cdot 4$ & $144 \cdot 0$ & $131 \cdot 3$ \\
\hline $\mathrm{SH}-12^{*}$ & & & & $3 \cdot 3$ & $80 \cdot 1$ & 137.8 & $128 \cdot 8$ \\
\hline
\end{tabular}

*-axially restrained

the buckling under axial compression. Table 5 (column 5) presents the buckling loads of the 12 models. Out of four tests in each group, two tests are conducted with axial constraint at the point, diametrically opposite of the loading point. The remaining two are carried out without axial constraint. It is well known that transverse shear buckling is followed or preceded by bending buckling (elephant foot) at the bottom of the diametrically opposite side, depending on the geometric parameters and the lever arm of load application. In the case of tests without axial constraint, it is observed that the bending buckling followed immediately after the shear buckling, figure 9. With the intention of preventing the bending buckling, the axial constraint is introduced. It is seen from the table, the buckling loads with axial constraint are lower than that without axial constraint. Figure 10 is the plot of load vs. horizontal displacement, measured at the top ring, diametrically opposite of the loading point. After reaching the limit load, the specimen undergoes gradual decrease in the load with increase in displacement. 


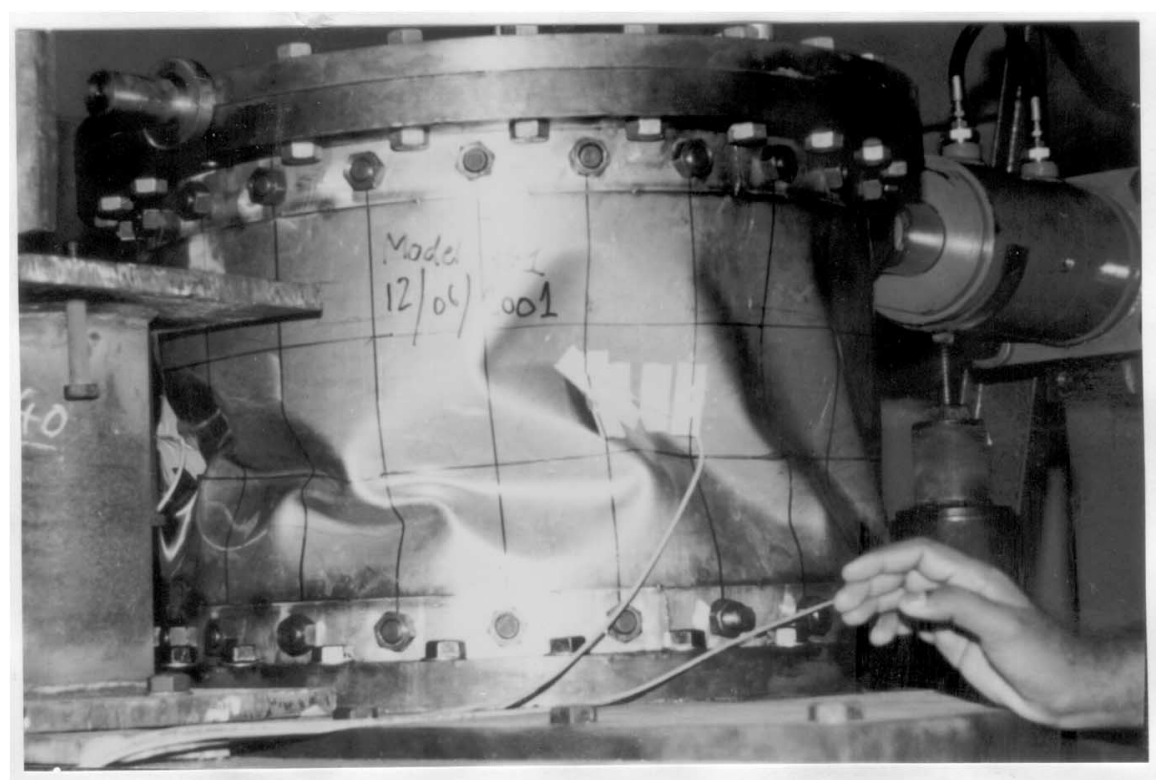

Figure 9. Photograph of the buckled shell - transverse shear, model no. SH-05 (formation of elephant foot buckling at opposite face of the loading).

That is, the shear buckling mode of failure is a slow process, unlike in the case of the axial buckling behavior, wherein the failure is a sudden phenomenon. In the case of specimen with axial constraint, load increases gradually with increase in displacement after buckling, leading to the bending buckling failure on the loading side itself, figure 11. Figure 12 shows

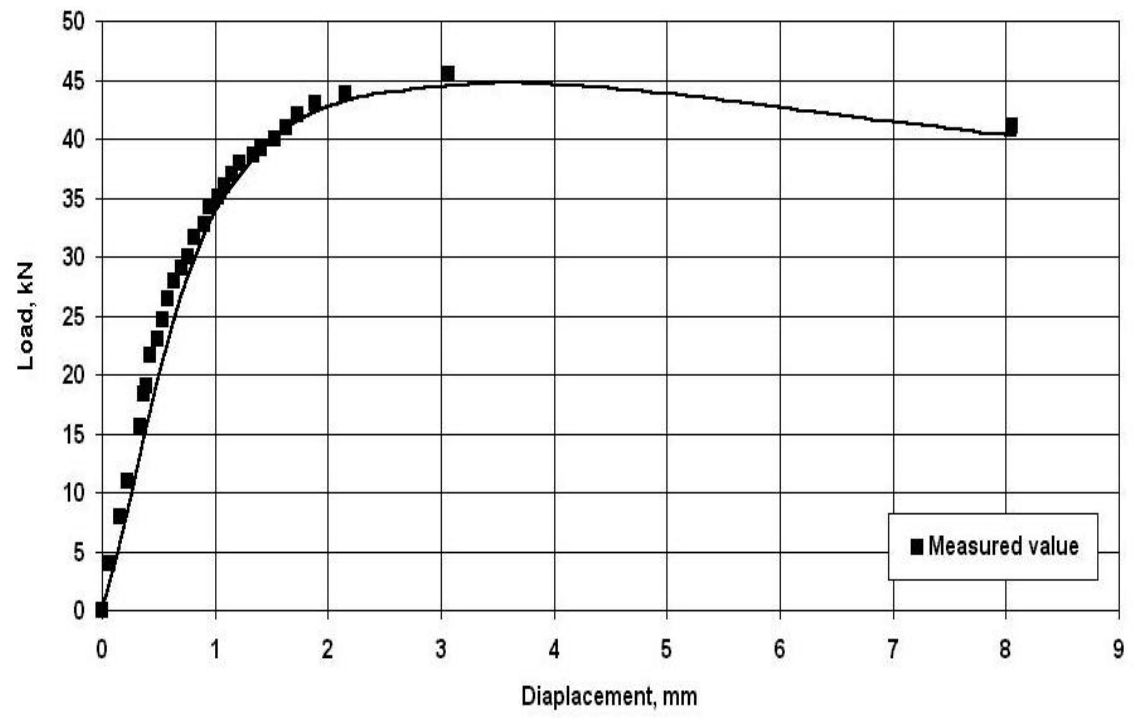

Figure 10. Load vs. horizontal displacement, model no. SH-01. 


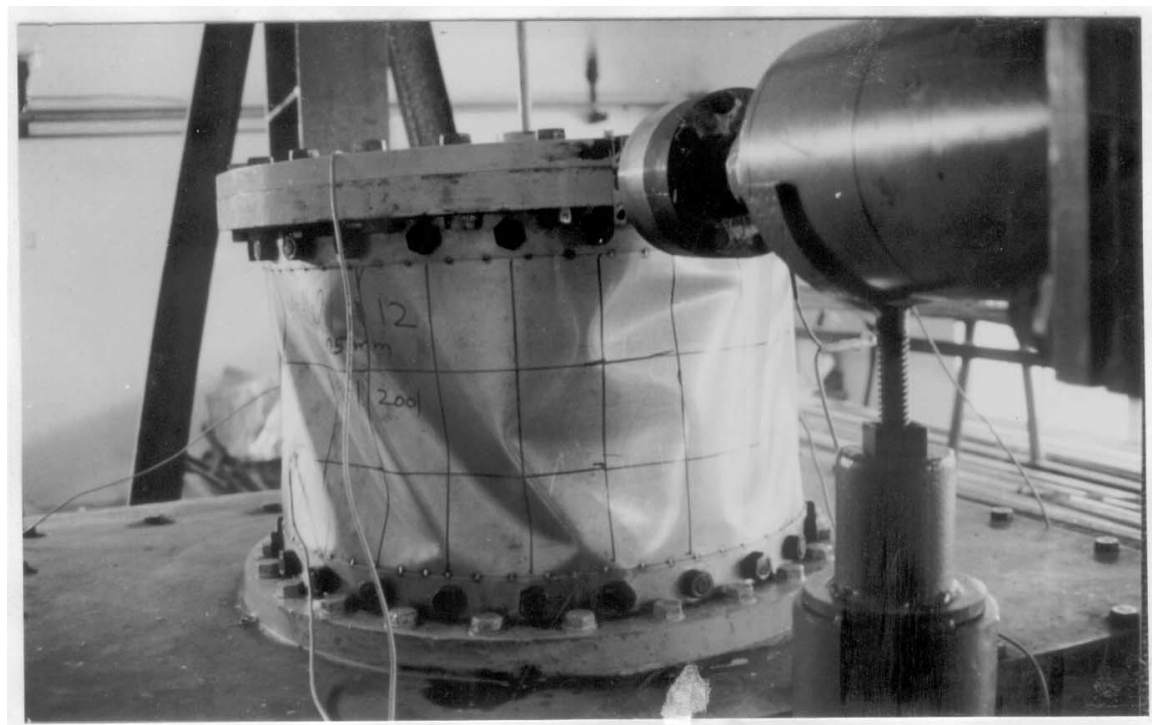

Figure 11. Photograph of the buckled shell - transverse shear, model no. SH-12 (axially constrained, bending buckling observed below the loading point).

the variations of 10 strain gauge values with load for model no. SH-09. The strain gauges are oriented at $+45^{\circ}$ and $-45^{\circ}$ with reference to the axial direction. Under transverse shear, one set of gauges shows tensile strains and the other set shows compressive strains. Initially, all the strains vary linearly with the load. The gauges in a pair show more or less the same

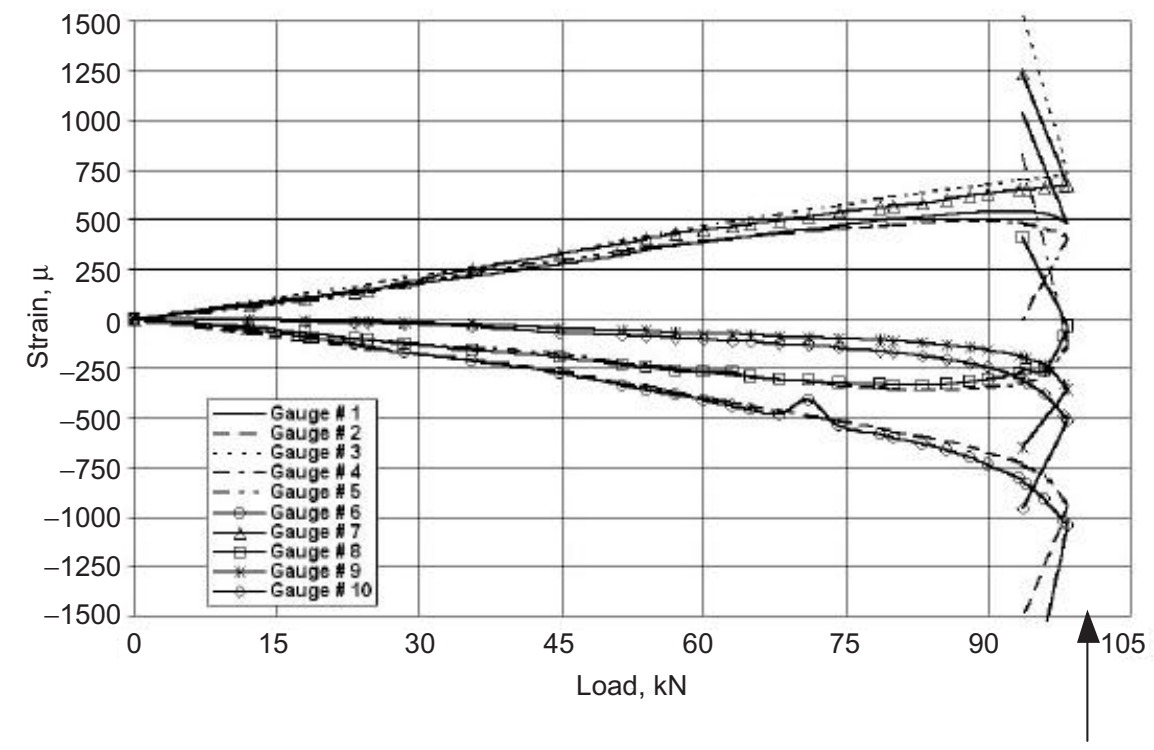

Figure 12. Load vs. strain - transverse shear, model no. SH-09 (arrow indicates buckling load). 
values. At failure, the strain gauges show sudden increase with decrease in load. The sudden changes in strains (indicated by the arrow) help to pin point the buckling load graphically.

Buckling behaviour under transverse shear is also modelled by the finite element method using the doubly curved shell element, S8R5 of ABAQUS in two ways: (i) geometry with real imperfection, FES-I and (ii) critical mode imperfect geometry, FES-II. As the shell under transverse shear loading has one plane of symmetry, these are the only two ways by which the buckling can be modelled in FEM. For FES-I, full cylinder is considered and the FE mesh consists of $120 \times 25$ (circumferential $\times$ axial) elements, which works out to 9240 nodes. The imperfections at all the nodal points are obtained from the experimentally measured imperfections at 1152 locations using Fourier series. In the second model, FES-II, the mesh consists of $180^{\circ}$ sector in the circumferential and full height in the axial directions. The imperfection shape is imposed in the form of critical eigen mode renormalised using the measured maximum imperfection of an experimental model and hence the name 'critical mode imperfect geometry'. The mesh size consists of $60 \times 25$ (circumferential $\times$ axial) elements. The numerically obtained buckling loads are given in the last two columns of table 5 . Also, given in the table are the buckling loads obtained from the linear and nonlinear FE analysis for the perfect geometries. With reference to the table, the following observations are made: (i) the experimental buckling loads are lower than the numerically obtained loads by about $25 \%$, a marginal reduction compared to that of the axial buckling case wherein the reduction is about $70 \%$ (table 4). (ii) the differences between the four sets of finite element values (linear, nonlinear, FES-I and FES-II) are marginal, (iii) FE modelling with imperfect geometry always predicts a lower value than perfect geometry, (iv) finite element modelling with axial constraint predicts buckling load higher than that without axial constraint, in spite of the fact that the imperfect geometry, FES-II, is obtained by using $\delta_{\max }$ as the renormalising factor (excessive imposition of imperfection). Based on the above observation, it is concluded that the transverse shear buckling load is not very sensitive to initial geometric imperfections.

\section{Conclusions}

(1) The initial geometric imperfections of models made by rolling and welding are of the order of about three times the wall thickness for most of the shell models. A few models have higher magnitudes of imperfection.

(2) The initial geometric imperfections affect the load carrying capacity. In the case of axial buckling, the reduction is considerable, nearly to one third of the classical value. The sensitivity is very high at smaller magnitudes of imperfection, (imperfection $<$ wall thickness). The sensitivity reduces for imperfections greater than the wall thickness. In the case of shear buckling, the reduction in load is marginal, leading to the conclusions that the transverse shear strengths are marginally sensitive to initial geometric imperfection.

(3) The extent of imperfection (imperfections present over an area) rather than the magnitude of imperfection (the highest value in a model) is important in assessing the buckling load.

(4) The shells under transverse shear load do not collapse immediately after buckling, unlike in the case of axial buckling. This is a useful structural characteristic in the context of design of cylindrical shell structures for seismic condition.

(5) In the case shear buckling tests with and without axial constraints, there are considerable differences both in the buckling load and failure locations between the two end conditions. These differences are not revealed by the finite element models. 
The authors gratefully acknowledge the excellent support and encouragement provided by S B Bhoje, S C Chetal, and Dr P Chellapandi, Indira Gandhi Centre for Atomic Research, Kalpakkam. Technical assistance provided by G Thomas and A Sadhasivam, Indian Institute of Technology Madras, Chennai are highly appreciated.

\section{List of symbols}

$\begin{array}{ll}e & \text { eccentricity; } \\ H & \text { effective height of the shell; } \\ L & \text { total height of the shell assembly; } \\ R & \text { radius; } \\ t & \text { wall thickness; } \\ \delta & \text { imperfection; } \\ \delta_{\max } & \text { maximum imperfection. }\end{array}$

\section{References}

ABAQUS FE: User's manual, version 5·5, Commercial Software Package Habitt, Karlsson \& Sorensen Inc., 1080, Main street, Pawtucket, Rhode Island, 02860-4867, USA

Athiannan K 2002 Buckling of imperfect cylindrical shells. Ph D thesis, Indian Institute of Technology - Madras, Chennai

Babcock C D, Sechler E E 1962 The effect of initial imperfections on the buckling stress of cylindrical shells. Report NASA TN D-1510, pp 135-142

Bushnell D 1981 Buckling of shells - Pitfall for designers. AIAA J. 19: 1183-1226

Dowling P J, Harding J E, Agelidis N, Fahy W 1982 Buckling of orthogonally stiffened cylindrical shells used in offshore engineering. In Buckling of shells (ed.) E Ramm Proc. A State-of-the-Art Colloquim (Berlin, Heidelberg, New York: Springer-Verlag)

Galletly G D, Blachut J 1985 Plastic buckling of short vertical cylindrical shells subjected to horizontal edge shear loads. Trans. ASME, J. Pressure Vessel Technol. 107: 101-106

Gerard G 1956 Compressive and torsional buckling of thin-wall cylinders in the yield region. National Advisory Committee for Aeronautics (NACA), Tech Note 3726

Kawamoto Y, Kodama T, Matsuura S 1993 The effect of thermal loads on buckling strength of cylindrical shells. Trans. 12th Int. Conf. on Structural Mechanics in Reactor Technology (New York: Elsevier Science) vol. E, pp 269-274

Kokubu K, Shigeta M, Madokoro M, Sakurai A, Nakamura H 1987 Buckling behaviour of short cylindrical shells under dynamic loads. Trans. 9th Int. Conference on Structural Mechanics in Reactor Technology (New York: Elsevier Science) vol. E, 167-172

Lee L H N 1962 Inelastic buckling of initially imperfect cylindrical shells subject to axial compression. J. Aerosp. Sci. 29: 87-95

Lundquist E E 1933 Strength tests of thin-walled duralumin cylinders in compression. NACA Report No. 473

Lundquist E E 1935 Strength tests of thin-walled duralumin cylinders in combined transverse shear and bending. NACA Report No. 523

Matsuura S, Nakamura H, Kokubu S, Ogiso S, Ohtsubo H 1995 Shear-bending buckling analyses of fast breeder reactor main vessels. Nuclear Eng. Design 153: 305-317

Miller C D, Grove R B 1986 Pressure testing of large-scale torispherical heads subjected to knuckle buckling. Int. J. Pressure Vessel Piping 22: 174-159

Murakami T, Yoguchi H, Hirayama H, Nakamura H, Matsuura S 1993 The effect of geometrical imperfection on shear buckling strength of cylindrical shells in bending. Trans. 12th Int. Conf. on Structural Mechanics in Reactor Technology (New York: Elsevier Science) vol. E, pp 257-268 
Saito K, Matsuura S, Nakajima M 2001 Shear-bending buckling tests of relatively thin-walled cylindrical shells. Trans. 16th Int. Conf. on Structural Mechanics in Reactor Technology, Washington D.C., USA, August, Division J, Paper No. 1527

Schneider M H, Jr 1996 Investigations of the stability of imperfect cylinders using structural models. Eng. Struct. 8: 792-800

Singer J, Haim Abramovich 1995 The development of shell imperfection measurement technique. Thin-walled Struct. 23: 379-398

Singer J 1997 Experimental studies in shell buckling. Proc. Structural Dynamics and Material Conference (New York: AIAA) 3: 1922-1932

Sobel L H, Newman S Z 1980 Plastic buckling of cylindrical shells under axial compression. Trans. ASME, J. Pressure Vessel Technol. 102: 40-44

Teng J G 1996 Buckling of thin shells: Recent advances and trends. ASME Appl. Mech. Rev. 49: 263-274

Tennyson R C 1964 Buckling of circular cylindrical shells in axial compression. AIAA J. 2: 1351-1353

Waeckel N, Jullien J F, Lefermann P 1984 Experimental studies on the instability of cylindrical shells with initial geometric imperfections. In Recent advances in nuclear component testing and theoretical studies on buckling (ed.) G Baylac pp 33-42

Weingarten V I, Morgan E J, Seide P 1965 Elastic stability of thin-walled cylindrical and conical shells under axial compression. AIAA J. 3: 500-505

Xiaoli D, Coleman R, Rotter J M 1996 Techniques for precise measurement of large-scale silos and tanks. J. Survey. Eng. 122: 14-25 